\title{
Investigating the Design Parameters for a Permeable Reactive Barrier Consisting of Nanoscale Zero-Valent Iron and Bimetallic Iron/Copper for Phosphate Removal
}

\author{
Osama Eljamal a*, Ian P. Thompson b, Ibrahim Maamoun a, Tamer Shubair a, Eljamal Kareman c, Khemmathin \\ Lueangwattanapong b, Yuji Sugihara a \\ a Environmental Fluid Science, Department of Earth System Science and Technology, Interdisciplinary Graduate School of \\ Engineering Sciences, Kyushu University, 6-1 Kasuga-Koen Kasuga, Fukuoka, Japan, 816-8580 \\ ${ }^{\mathrm{b}}$ Department of Engineering Science, University of Oxford, Parks Road, Oxford, OX1 3PJ, UK \\ ${ }^{\mathrm{c}}$ Department of Clinical Pharmacology, Graduate School of Medical Sciences, Kyushu University, Fukuoka, Japan \\ *Corresponding author email: osama-eljamal@kyudai.jp
}

\begin{abstract}
There is growing in interest in deploying nanoscale zero valent iron (NZVI) in permeable reactive barriers (PRBs) for groundwater remediation. In the present study a series of packed-column experiments were conducted in order to investigate the effectiveness of phosphorus removal from groundwater using NZVI and bimetallic $\mathrm{NZVI/Cu}$ as a reactive material within permeable reactive barriers (PRBs), also to help to inform on the design of the PRB. Experiments were conducted using a lab-scale column of $65 \mathrm{~cm}$ length and $10 \mathrm{~cm}$ inner diameter using two types of silica sand, river sand and standard sand, as a filling porous material. Seven sets of column experiments were established in order to investigate the effect of: different delivery methods of the reactive material into porous media (layers-packing or injection); modifying NZVI composition by copper addition; supporting materials and the flowrate change. The physical characteristics of the reactive and supporting materials were investigated using X-ray diffraction (XRD) analysis, transmission electron microscopy (TEM), scanning electron microscopy with energy dispersive X-ray spectroscopy (SEM-EDS). These analyses revealed that doping of NZVI surface with copper enhanced performance in terms of phosphorus removal 2.2 times more than pure NZVI. Moreover, the lower flowrate $(10 \mathrm{ml} / \mathrm{min})$ demonstrated improved phosphorus removal by $22 \%$ compared with higher flowrate $(60 \mathrm{ml} / \mathrm{min})$. Additionally, the contact time between NZVI and phosphorus had a crucial effect on the long-term phosphorus removal efficiency and should to be considered in the preliminary design of PRBs. Overall, geochemical properties as well as the characteristics of the supporting materials were considered to be key parameters in the removal process of phosphorus by bimetallic NZVI/Cu. Further studies should be performed based on a statistical analysis model in order to integrate such presented results in the determination of the optimum design and conditions of PRBs towards better performance in the real in-situ remediation applications.
\end{abstract}

\section{Keywords}

NZVI; Bimetallic NZVI; Phosphorus removal; Packed-column; Groundwater remediation.

\section{Introduction}

Phosphorus (P) is a critical chemical element for the growth of microorganisms and plants as long. The main source of $\mathrm{P}$ is geological phosphate which is expected to become exhausted within a century (Eljamal et al. 2013, Cordell et al. 2009). However, its excessive and at times indiscriminate use in agricultural fertilizers, presence in many industrial wastes, and landfill waste disposal are some of the causes for the presence of high 
concentrations of phosphorus in water systems (Liu et al. 2013, Wen et al. 2014). Recovery of P from water has become an essential task to solve $\mathrm{P}$ depletion problem and to reduce its negative effects on the ecosystem. A high concentration of $\mathrm{P}$ in the water causes eutrophication which resulting in the depletion of oxygen concentration that can adversely affect aquatic life (Penn and Warren 2009, Hauduc et al. 2015). Three forms of dissolved P are detected in water; organic, ortho and poly phosphates (Eljamal et al. 2014, Mezenner and Bensmaili 2009). To counter this, several methods are available for removing $\mathrm{P}$ from water including biological, adsorption, precipitation, co-precipitation and crystallization (Almeelbi and Bezbaruah 2012, Eljamal et al. 2012). A more recent approach which has attracted significant attention is Zero-valent iron (ZVI) which is most commonly used adsorbents of water contaminants. At nano-scale ZVI represents a novel technology for environmental remediation including the $\mathrm{P}$ removal from water. ZVI has the additional advantage that it is non-toxic and its core-shell structure feature, gives it the ability to remove phosphorus employing different removal mechanisms such as adsorption, precipitation and co-precipitation (Khalil et al. 2017, Khalil et al. 2018, Tosco et al. 2014). Indeed its adsorption capacity for phosphorus especially with elevated concentrations compares very well to goethite (Liu et al. 2013, Chitrakar et al. 2006), kaolinite (Penn and Warren 2009), and activated carbon (Hussain et al. 2011).

In our previous study of phosphorus removal from aqueous solution by NZVI, we demonstrated that the high efficiency of phosphorus removal by NZVI $(30 \mathrm{mg} / \mathrm{g})$ and even higher efficiency $(50 \mathrm{mg} / \mathrm{g})$ in the presence of copper (Eljamal et al. 2016). Almeelbi et al. also conducted a batch test to assist the NZVI ability to remove $\mathrm{P}$ from the aqueous solution, showing that the efficacy of the NZVI was 13.9 times higher than ZVI with $\mathrm{P}$ adsorption capacity of $24.4 \mathrm{mg} / \mathrm{g}$ at $\mathrm{pH} 4.0$ (Almeelbi and Bezbaruah 2012). In another study, Tu et al. investigated nano-scale bimetal ferrites for $\mathrm{P}$ removal from water, where the results indicated that the $\mathrm{P}$ adsorption capacity (13.5 mg/g) at pH 2.6 (Tu and You 2014). Another study reported that using ZVI in packed columns on phosphate removal from aqueous solution demonstrated a homogeneous distribution of $\mathrm{P}$ along the column with adsorption capacity $132 \mathrm{mg} / \mathrm{g}$ (Sleiman et al. 2016).

Despite its exceptional properties, NZVI still has some drawbacks when it comes to the real environmental remediation including the poor mobility, particles agglomeration as well as the limited suspension stability (Guan et al. 2015). Hence, several modifications of the material have been studied in order to overcome such drawbacks. Hybridizing NZVI with the addition of other metals on its surface is known to improve the redox potential of the composite and reduced aggregation potential. Several metals have been used in the bimetallic NZVI composites such as palladium (Pd) (Lien and Zhang 2005, 2007, Wang et al. 2008), Nickel (Ni) (Schrick et al. 2002), and silver (Ag) (Xu and Zhang 2000). Meanwhile, previous studies have reported the usage of copper $(\mathrm{Cu})$ with NZVI serving as a catalyst resulting in enhanced reactivity of the particles (Khalil et al. 2016, Shubair et al. 2018a, Shubair et al. 2018b).

Several researchers have investigated the efficiency of NZVI and bimetallic NZVI/Cu in phosphorus removal. However, bench-scale tests are necessary to get some understanding of their performance in field conditions. Therefore, column tests using porous material is an informative intermediate step towards full-scale applications. Most of the previous studies using ZVI/NZVI packed columns have focused on the removal of heavy metals from water (Eljamal et al. 2014, Mak et al. 2011, Ponder et al. 2000). Furthermore, there have been very few reports of the removal of P using ZVI packed-column as technique to inform on the design of 
the PRB, and even less information on phosphorus removal using NZVI or Bimetallic Iron/Copper (NZVI/Cu) or how the effectiveness of the materials may be influence field condition, local porous materials and flow rates.

In the present study, the main objective are to propose a rational design of PRB for phosphorus removal by $\mathrm{NZVI}$ and/or $\mathrm{NZVI/Cu}$. In order to achieve this twelve packed-column experiments were conducted consisting of different operating conditions in order to achieve the main objectives of this study which can be briefly summarized as follows:

1. Investigating the effectiveness of phosphorus removal from groundwater using NZVI as a reactive material within permeable reactive barriers (PRBs).

2. Assessing the enhancement of phosphorus removal capacity of NZVI by Cu doping.

3. Exploring the interaction between the solid and liquid phases by measuring phosphorus and iron concentration down the layers and at the columns outlet, as well as characterizing the solid samples of NZVI, NZVI/Cu and sand.

4. Investigating the effect of different determinants within the permeable reactive barrier installation process or during the phosphorus removal, including the effect of: PRB configuration as one reactive layer or double series reactive layers separated by sand layer, reactive material delivery method as packed layer or direct injected in the sand layer, reactive material state as pure reactive material layer or mixed reactive material with sand, feeding solution as pure phosphorus solution or simulated groundwater, constant flow rate or variable flow rate), as well as the longevity effect of long and short experiments).

5. Investigating several geochemical parameters which potential affects the removal process of phosphorus from groundwater in the presence of either NZVI or bimetallic NZVI, such as $\mathrm{pH}$, oxidation reduction potential (ORP), and dissolved oxygen (DO) as well as the degree of interference of groundwater ions on phosphorus removal performance.

\section{Materials \& Methods}

\subsection{Materials}

The following chemicals and materials were used in this study as received without any pre-modification. Sodium borohydride $\left(\mathrm{NaBH}_{4}, 98.0 \%\right.$, Sigma-Aldrich Inc., USA), and ferric chloride hexahydrate $\left(\mathrm{FeCl}_{3} .6 \mathrm{H}_{2} \mathrm{O}, 99.0 \%\right.$, Junsei Chemical Co., Japan) for NZVI synthesis. Anhydrous copper chloride $\left(\mathrm{CuCl}_{2}\right.$, 99.9\%, Aldrich Inc., USA) was used to synthesize bimetallic NZVI. For phosphorus solution preparation, potassium dihydrogen phosphate $\left(\mathrm{KH}_{2} \mathrm{PO}_{4} 99.5 \%\right.$, Kanto Chemical Co., Japan) was used. Moreover, sodium sulphate $\left(\mathrm{Na}_{2} \mathrm{SO}_{4}, 99 \%\right.$, Wako Co., Japan), magnesium chloride hexahydrate $\left(\mathrm{MgCl}_{2} .6 \mathrm{H}_{2} \mathrm{O}, 97 \%\right.$, Wako Co., Japan, sodium bicarbonate $\left(\mathrm{NaHCO}_{3}, 99 \%\right.$, Wako Co., Japan), and calcium chloride dihydrate $\left(\mathrm{CaCl}_{2} .2 \mathrm{H}_{2} \mathrm{O}\right.$, 70-79\%, Junsei Chemical Co., Japan) were used for simulated groundwater. sodium hydroxide ( $\mathrm{NaOH}, 97 \%$, Wako Co., Japan), hydrochloric acid ( $\mathrm{HCl}, 35-37 \%$, Wako Co., Japan), and pH buffer solution (Sansyo Co., Japan) were used for $\mathrm{pH}$ adjustment. All solutions were prepared using deionized water along with $20 \mathrm{~min}$ deoxygenating by nitrogen gas. Furthermore, standard sand (ASONE Corp., Japan) and river sand (Kobaya, Miyazaki, Japan) were used as porous medium for column experiments.

\subsection{Synthesis of NZVI}


NZVI was synthesized following the chemical reduction equation of ferric chloride by sodium borohydride (Eljamal et al. 2016, Hwang et al. 2011):

$$
2 \mathrm{FeCl}_{3}+6 \mathrm{NaBH}_{4}+18 \mathrm{H}_{2} \mathrm{O} \rightarrow 2 \mathrm{Fe}^{0}+21 \mathrm{H}_{2}+6 \mathrm{~B}(\mathrm{OH})_{3}+6 \mathrm{NaCl}
$$

In order to synthesize $10 \mathrm{~g}$ of NZVI the following steps were undertaken. Firstly, reductant solution was prepared by dissolving amount of $35 \mathrm{~g}$ sodium borohydride in $1250 \mathrm{~mL}$ of deoxygenated deionized water (DDIW). Secondly, 50g of ferric chloride hexahydrate was dissolved in $1250 \mathrm{~mL}$ of DDIW to prepare the precursor solution which was kept in $5000 \mathrm{~mL}$ four-neck glass flask at constant temperature $25 \pm 0.5^{\circ} \mathrm{C}$ using water bath. Afterward, the reductant solution was pumped drop-wisely into the synthesis flask at a rate of 1 $\mathrm{L} / \mathrm{h}$ along with vigorous mechanical mixing at $250 \mathrm{rpm}$. The mixture was left for a $20 \mathrm{~min}$ aging time to ensure the reaction was complete. Furthermore, nitrogen gas was purged continuously into the mixture during the whole synthesis to provide the anaerobic atmosphere. Finally, the resultant black precipitates were collected by vacuum filtration and washed three times with DDIW before using directly in the experiments.

\subsection{Synthesis of $\mathrm{NZVI/Cu}$}

The bimetallic nano iron particles $(\mathrm{NZVI} / \mathrm{Cu})$ were synthesized following the same formerly mentioned synthesis procedure of NZVI except for the addition of $\mathrm{CuCl}_{2}$ to the ferric chloride solution prior the injection of reductant solution. The addition of $\mathrm{CuCl}_{2}$ was at rate of $0.5 \mathrm{~g}$ per $10 \mathrm{~g}$ of NZVI (mass ratio), which was considered as the optimum addition rate for promoted efficiency (Khalil et al. 2016). The redox effect of the addition of $\mathrm{Cu}^{2+}$ to NZVI was based on the following reaction:

$$
\mathrm{Fe}^{0}+\mathrm{Cu}^{2+} \rightarrow \mathrm{Fe}^{2+}+\mathrm{Cu}^{0}
$$

\subsection{Characterization}

The physical characteristics of both NZVI and NZVI/Cu were investigated. X-ray diffraction (XRD) analysis was performed in order to investigate the crystallinity and the exact composition of the synthesized particles. Samples were analyzed in X-ray diffractometer (XRD, TTR, Rigaku, Tokyo, Japan) using Cu K $\alpha$ radiation (k $=1.5418 \AA$ ) operating at $40 \mathrm{kV}$ and $200 \mathrm{~mA}$ with scanning rate of $3^{\circ} \mathrm{min}^{-1}$ and scanning angle ranged between $3^{\circ}$ and $90^{\circ}$ (Eljamal et al. 2016). Furthermore, transmission electron microscopy (TEM, JEM-ARM 200F, JEOL Co., Japan) was used to investigate the particles morphology. Additionally, scanning electron microscopy (JSM-6060LA/VI, JEOL Co., Japan) connected with energy dispersive X-ray spectroscopy (EDS) was used to determine the elemental composition of the particles. In order to measure the Brunauer-EmmettTeller specific surface area (BET SSA) of the synthesized particles, surface area analyzer (Micromeritics 3Flex, USA) was used based on $\mathrm{N}_{2}$ adsorption methodology at $77 \mathrm{~K}$ (Zeng et al. 2017). Moreover, particle size analyzer (SALD-2300, Shimadzu Co., Japan) was used to estimate the size of synthesized particles after being ultrasonicated in ethanol for $30 \mathrm{~min}$.

\subsection{Analysis}

Phosphorus concentration in solution samples was colorimetrically measured via UV-Vis spectrophotometer (DR 3900, Hach Co., USA) using ascorbic acid method (USEPA PhosVer 3) at $880 \mathrm{~nm}$ (Eaton et al. 2005). Additionally; $\mathrm{pH}$, and oxidation reduction potential (ORP) measurements were obtained for samples and solutions using pH/ORP digital meter (D-72, LAQUAact, Horiba Co., USA). Dissolved oxygen (DO) was 
also recorded using portable digital-meter (HQ30d flexi, Hach Co., USA).

\subsection{Column experiments}

Column experiments were conducted in Plexiglas columns with dimensions of $65 \mathrm{~cm}$ length and $10 \mathrm{~cm}$ inner diameter (Fig. 1). Two types of silica sand, river sand and standard sand, were used as a filling porous material at the top and the bottom of the columns and also as a supporting material for NZVI and NZVI/Cu in the reactive mixture at the middle of the columns with (Fe/sand) mixing mass ratio of 0.01 . River sand was selected as a supporting material because of its high drainage characteristics as well as the low cost. Moreover; unlike standard sand, river sand represented the real state of the aquifer material in field without any treatment of the impurities on the sand surface. The configuration of the reactive layers as well as the operating conditions were modified in order to investigate several factors that might affect the performance of the presented permeable reactive barrier (PRB) design in phosphorus removal (Table. 1). Therefore, the flowchart displayed in (Fig. 2) shows the framework of the multiple conducted experiments and the considered factors for phosphorus removal through the columns. Column 1 (C1) was integrated as a control column containing only river sand. Key factors of the current PRB design were investigated as follows:

1- The efficiency of modifying the surface of NZVI with the addition of Copper $(\mathrm{NZVI} / \mathrm{Cu})$ was examined where flowrate, supporting material, and state of reactive material remained without change $(\mathrm{C} 2, \mathrm{C} 4)$ and (C3, C5).

2- Secondly, the effect of multi-layer design of PRB on phosphorus removal was investigated (C2, C3) and $(\mathrm{C} 4, \mathrm{C} 5)$.

3- Then, the influence of changing the reactive material state inside the columns whether supported on sand, pure, or injected with a controlled rate (C2, C6, and $\mathrm{C} 7)$.

4- Based on the high performance of (C4) in the former experiments, the efficiency of the two supporting types of sand in removal performance was examined $(\mathrm{C} 4, \mathrm{C} 8)$.

5- Moreover, operating with variable flowrate (Table. 2) was performed in (C4, C9).

6- The interference of groundwater ions (Table. 3) was simulated in (C4, C10).

7- Finally, the long-term experiments were conducted (C11, C12).

Aqueous solution with initial phosphorus concentration of $25 \mathrm{mg} / \mathrm{L}$ was pumped downward into the columns using a peristaltic pump. The initial $\mathrm{pH}, \mathrm{ORP}$, and $\mathrm{DO}$ values of the feeding $\mathrm{P}$-solution were $7,-25 \mathrm{mV}$, and 8 $\mathrm{mg} / \mathrm{L}$ respectively. The top sand layer $(10 \mathrm{~cm}$ length) provided a uniform flow of the phosphorus solution inside the column. Moreover, mesh filters were used at the inlet and outlet of the columns in order to prevent the inflow and the outflow of soil particles. Effluent treated water samples as well as samples along the columns were collected periodically for phosphorus and concentration analysis along with the daily measurements of $\mathrm{pH}, \mathrm{ORP}$, and DO of outlet samples. All the column results are presented as average data of duplicate experiments. 
Table. 1 Configuration of column experiments

\begin{tabular}{|c|c|c|c|c|c|c|c|c|c|}
\hline $\begin{array}{c}\text { Column } \\
\text { No. }\end{array}$ & $\begin{array}{l}\text { No of } \\
\text { layers }\end{array}$ & $\begin{array}{c}\text { Layer } \\
\text { Depth }(\mathrm{cm})\end{array}$ & $\begin{array}{l}\text { Reactive } \\
\text { material }\end{array}$ & $\begin{array}{c}\text { Dosage } \\
(\mathrm{g})\end{array}$ & State & $\begin{array}{c}\text { Supporting } \\
\text { material }\end{array}$ & $\begin{array}{l}\text { Flowrate } \\
\text { (ml/min) }\end{array}$ & $\begin{array}{l}\text { Feeding } \\
\text { solution }\end{array}$ & $\begin{array}{c}\text { Duration } \\
\text { (days) }\end{array}$ \\
\hline $\begin{array}{c}\mathrm{C1} \\
\text { (control) }\end{array}$ & - & $x^{2}+2 \times$ & 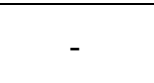 & (2) & - & \multirow{7}{*}{ River sand } & 15 & \multirow{9}{*}{ P-solution ${ }^{1}$} & 14 \\
\hline $\mathrm{C} 2$ & 1 & 20 & NZVI & 20 & Mixture & & 15 & & 14 \\
\hline C3 & 2 & 10 & NZVI & 20 & Mixture & & 15 & & 14 \\
\hline $\mathrm{C} 4$ & 1 & 20 & $\mathrm{NZVI} / \mathrm{Cu}$ & 10 & Mixture & & 15 & & 14 \\
\hline C5 & 2 & 10 & $\mathrm{NZVI/Cu}$ & 10 & Mixture & & 15 & & 14 \\
\hline C6 & 1 & - & NZVI & 10 & Pure & & 15 & & 14 \\
\hline C7 & - & - & NZVI & $\begin{array}{c}10 \\
(2 \mathrm{~g} / \text { day })\end{array}$ & Injection & & 15 & & 14 \\
\hline C8 & 1 & 20 & $\mathrm{NZVI/Cu}$ & 10 & Mixture & \multirow[t]{2}{*}{ Standard sand } & 15 & & 14 \\
\hline C9 & 1 & 20 & $\mathrm{NZVI} / \mathrm{Cu}$ & 10 & Mixture & & $60-10$ & & 14 \\
\hline C10 & 1 & 20 & $\mathrm{NZVI} / \mathrm{Cu}$ & 10 & Mixture & \multirow{3}{*}{$\succ$ River sand } & 15 & $\begin{array}{c}\text { Simulated } \\
\mathrm{GW}^{2}\end{array}$ & 14 \\
\hline C11 & 2 & 10 & NZVI & 10 & Mixture & & 5 & \multirow{2}{*}{ P-solution } & 90 \\
\hline $\mathrm{C} 12$ & 2 & 10 & $\mathrm{NZVI} / \mathrm{Cu}$ & 10 & Mixture & & 5 & & 90 \\
\hline
\end{tabular}

${ }^{1} \mathrm{P}$-solution: phosphorus solution ${ }^{2} \mathrm{GW}$ : Groundwater

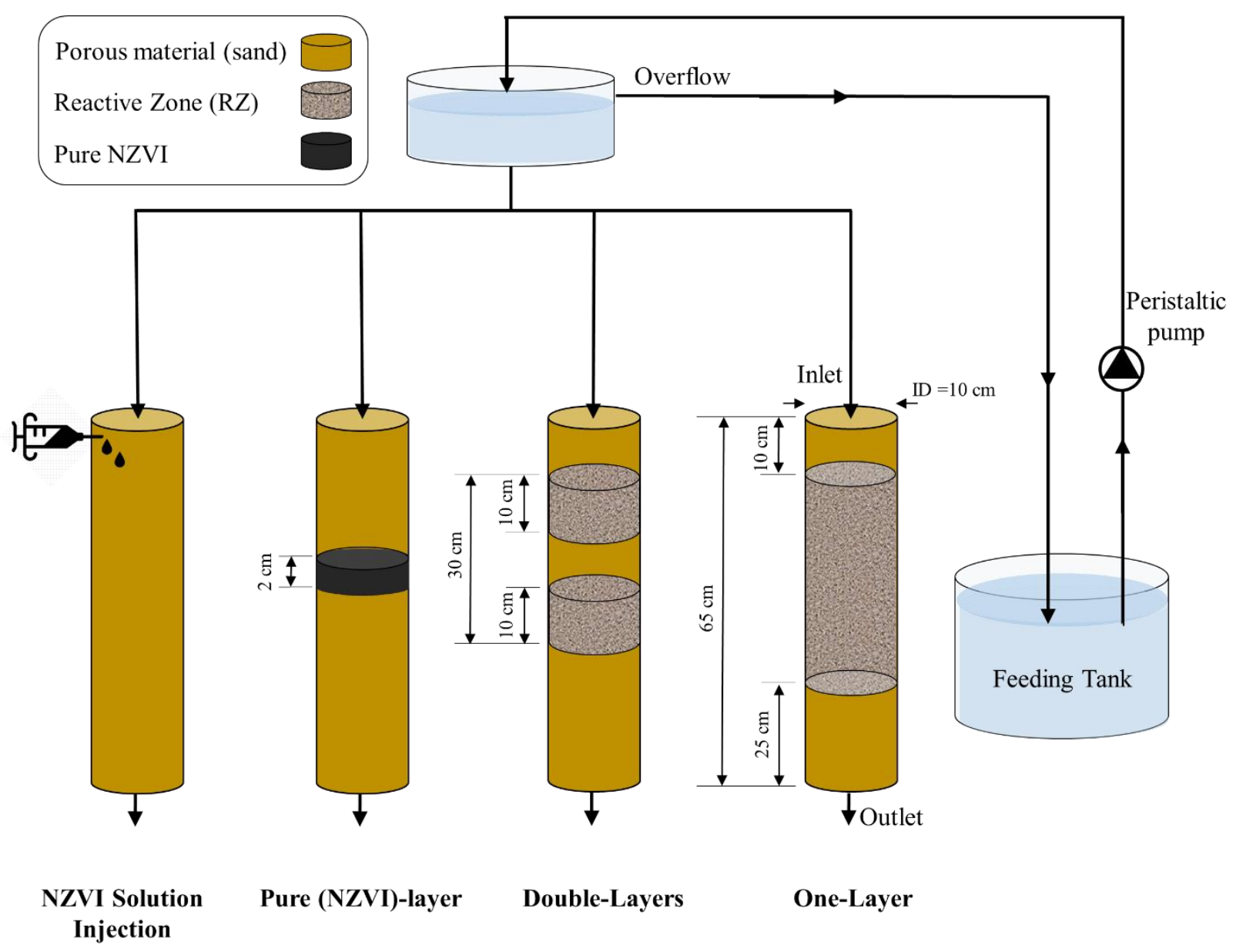

Fig. 1 Schematic diagram of the column system 


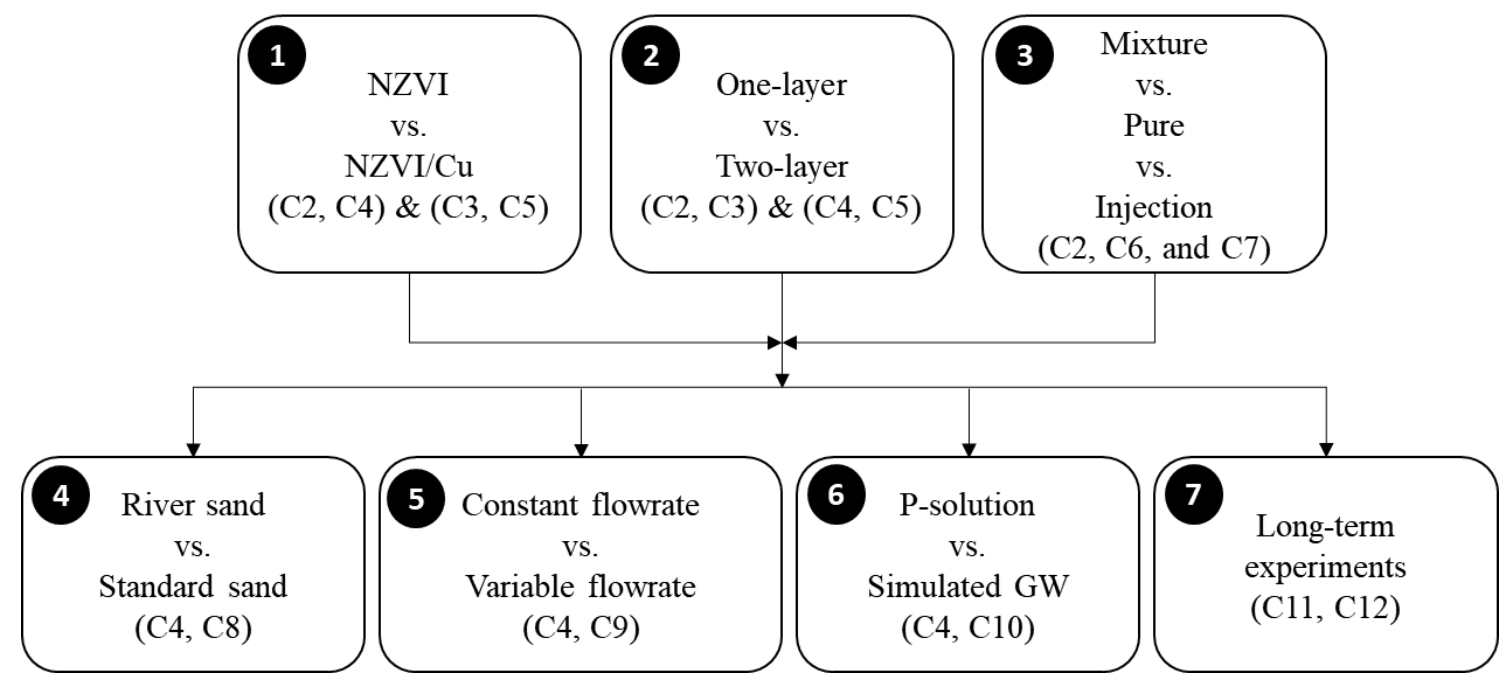

Fig. 2 Framework for sets of column experiments and factors investigated

Table. 2 Flowrate variation in C9

\begin{tabular}{c|c}
\hline Time $(\mathrm{hr})$ & Flowrate $(\mathrm{mL} / \mathrm{min})$ \\
\hline $0-12$ & 60 \\
$12-24$ & 40 \\
$24-36$ & 30 \\
$36-48$ & 15 \\
48-end of experiment & 10 \\
\hline
\end{tabular}

Table. 3 Chemical compositions of simulated groundwater used in $\mathrm{C} 10$

\begin{tabular}{c|ccccccc}
\hline Chemical compound & $\mathrm{Ca}^{2+}$ & $\mathrm{Cl}^{-}$ & $\mathrm{Na}^{+}$ & $\mathrm{SO}_{4}^{2-}$ & $\mathrm{HCO}_{3}^{-}$ & $\mathrm{Mg}^{2+}$ & $\mathrm{P}$ \\
Concentration $(\mathrm{mg} / \mathrm{L})$ & 31.36 & 79.0 & 131.0 & 203.0 & 89.58 & 8.07 & 25.0 \\
\hline$(\mathrm{pH}=7, \mathrm{ORP}=-55 \mathrm{mV}$ and $\mathrm{DO}=10 \mathrm{mg} / \mathrm{L})$
\end{tabular}

\subsection{Statistical analysis}

One-way ANOVA test was performed by GraphPad Software for Windows (San Diego California USA) to evaluate the significant difference between the results obtained from columns, using $95 \%$ confidence interval, i.e. $\mathrm{p}<0.05$ indicating statistical significance.

\section{Results \& Discussion}

\subsection{Characterization of synthesized nanoparticles}

The two peaks at $2 \theta=44.8^{\circ}$ and $82.6^{\circ}$ in the XRD analysis of fresh mixture samples (NZVI-sand and $\mathrm{NZVI} / \mathrm{Cu}$-sand) confirmed the presence of zero-valent iron $\left(\alpha-\mathrm{Fe}^{0}\right)$. Meanwhile, the weak peaks of hematite $\left(\mathrm{Fe}_{2} \mathrm{O}_{3}\right)$ in Fig. 3a indicated the presence of a relatively small amount of iron oxides which contributed significantly in phosphorus adsorption. Furthermore, the apparent peaks of copper ferrite $\left(\mathrm{CuFe}_{2} \mathrm{O}_{4}\right)$ in the spent samples of NZVI/Cu-sand mixture (Fig. 3b) endorsed that phosphorus ions were co-precipitated on the surface of the bimetallic iron particles following this reaction (Bard et al. 1980):

$$
\mathrm{CuO}+\mathrm{Fe}_{2} \mathrm{O}_{3} \rightarrow \mathrm{CuFe}_{2} \mathrm{O}_{4}
$$


Additionally, TEM investigation of synthesized NZVI showed a chain-like aggregated structure and nearly spherical shape of the particles as displayed in Fig. 4a (Zhang et al. 2011). Meanwhile, due to copper addition, a relatively separate distribution was observed for the spherical $\mathrm{NZVI/Cu}$ particles in the exhibited microscopic morphology in Fig. 4b. Moreover, the areas with brighter color in the images represented the thin iron oxide/hydroxide outer shell on both of NZVI and NZVI/Cu surfaces.

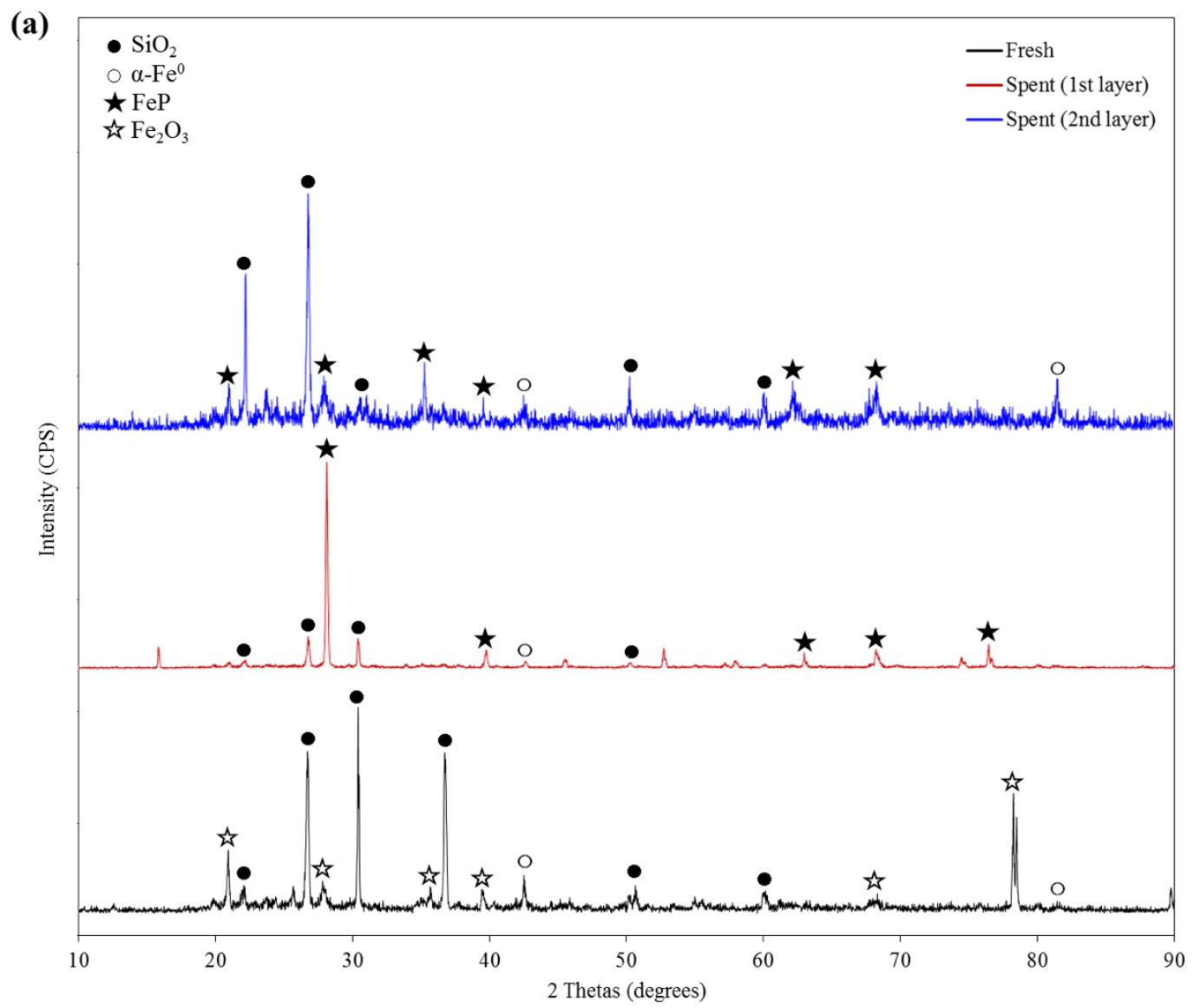




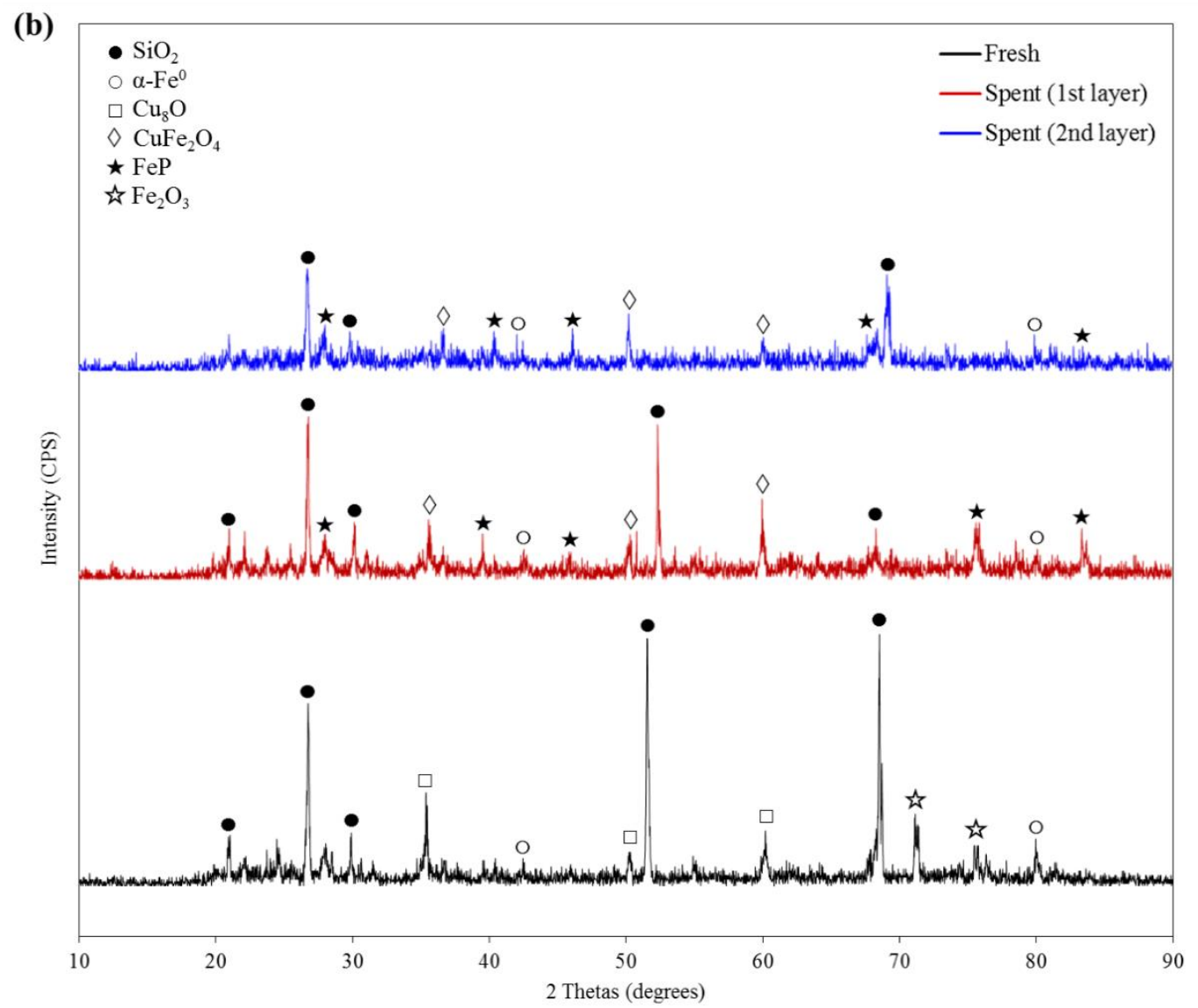

Fig. 3 XRD patterns for fresh and spent reactive mixture samples of: (a) NZVI-sand, and (b) NZVI/Cu-sand
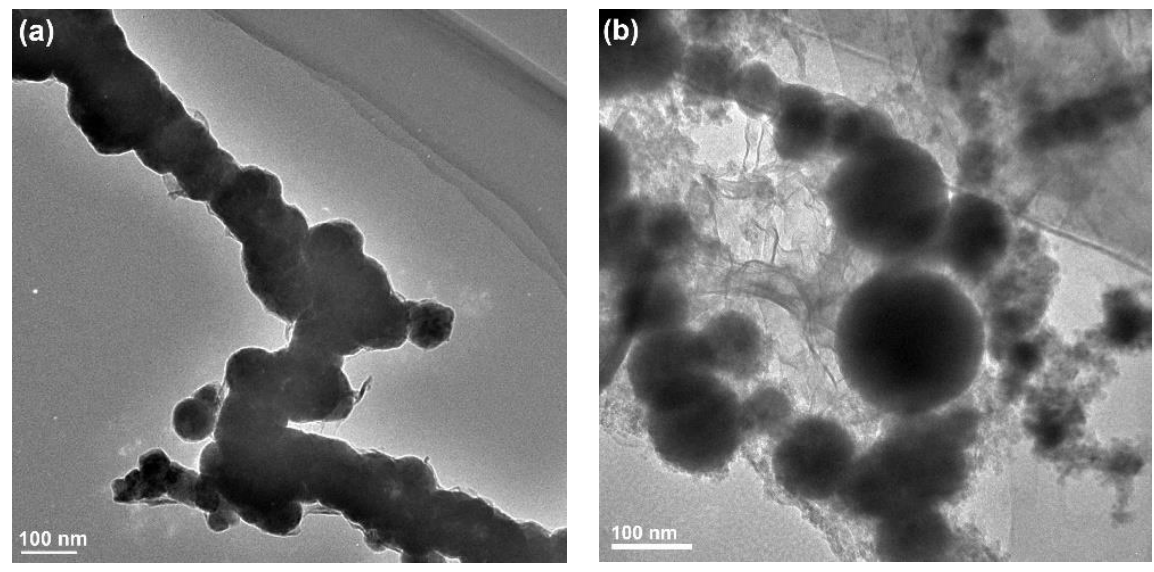

Fig. 4 TEM images of (a) NZVI and (b) NZVI/Cu

Surface morphology of NZVI and NZVI/Cu particles was further analyzed by SEM images. The irregular microscale of sand particles was clearly observed in the reactive sand mixture with either iron or bimetallic iron (see Fig. S1a \& b in Supplementary Materials). The EDS analysis for spent samples of both NZVI and bimetallic NZVI sand mixtures was performed in order to determine the elemental composition. Si, Fe and O were the main elemental components in the EDS spectra of the spent NZVI-sand sample (Fig. 5a). Whereas, the same former elements were detected as well as a small amount of copper $(\mathrm{Cu})$ in the spent $\mathrm{NZVI} / \mathrm{Cu}$-sand sample (Fig. 5b). Concurrently, silicon (Si) peaks were comparatively stronger than iron (Fe) peaks in the two EDS spectrums which could be attributed to the Fe/sand mixing mass ratio of 0.01 . Moreover, weak phosphorus (P) peak was found in the EDS spectra of the reacted samples confirming the adsorption process. Some neglected traces of $\mathrm{Al}, \mathrm{Mg}$ and $\mathrm{Na}$ was found in the samples. The SEM-EDS analysis for the fresh 
samples of NZVI and the bimetallic mixtures is introduced in Fig. S1c \& d respectively in the Supplementary Materials. The BET measurements implied specific surface area values of 17.32 and $32.4 \mathrm{~m}^{2} / \mathrm{g}$ for NZVI and $\mathrm{NZVI/Cu}$ respectively, which was close to previously reported values (Shubair et al. 2018a, Zhang et al. 2011, Liu et al. 2005, Yuvakkumar et al. 2011). Meanwhile, particle size analysis demonstrated a size distribution within the range of about 13-70 and 15-117 $\mathrm{nm}$ for iron and bimetallic iron particles respectively. Whereas, the average particle size was $44 \mathrm{~nm}$ for NZVI and $24 \mathrm{~nm}$ for $\mathrm{NZVI} / \mathrm{Cu}$.

(a)

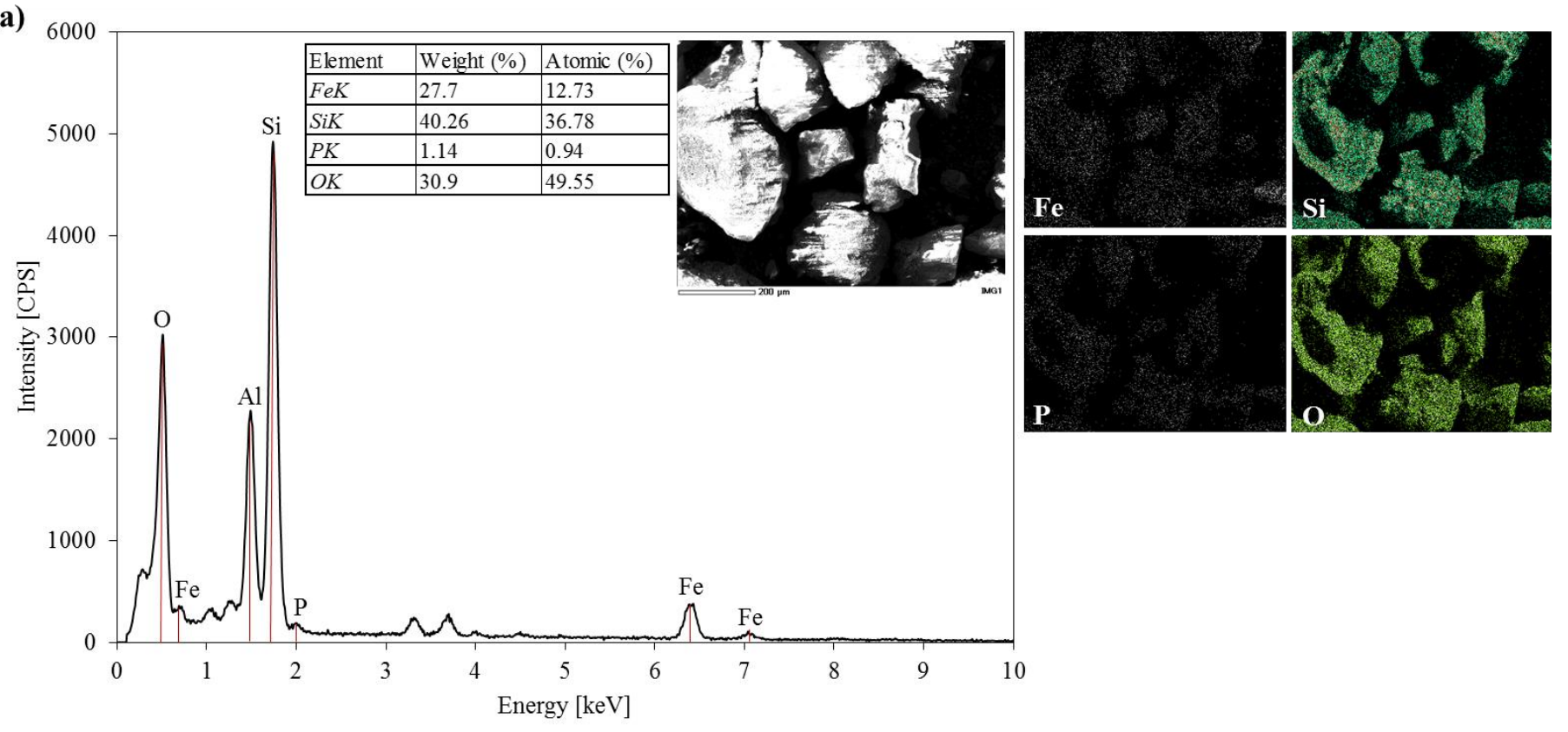

(b)

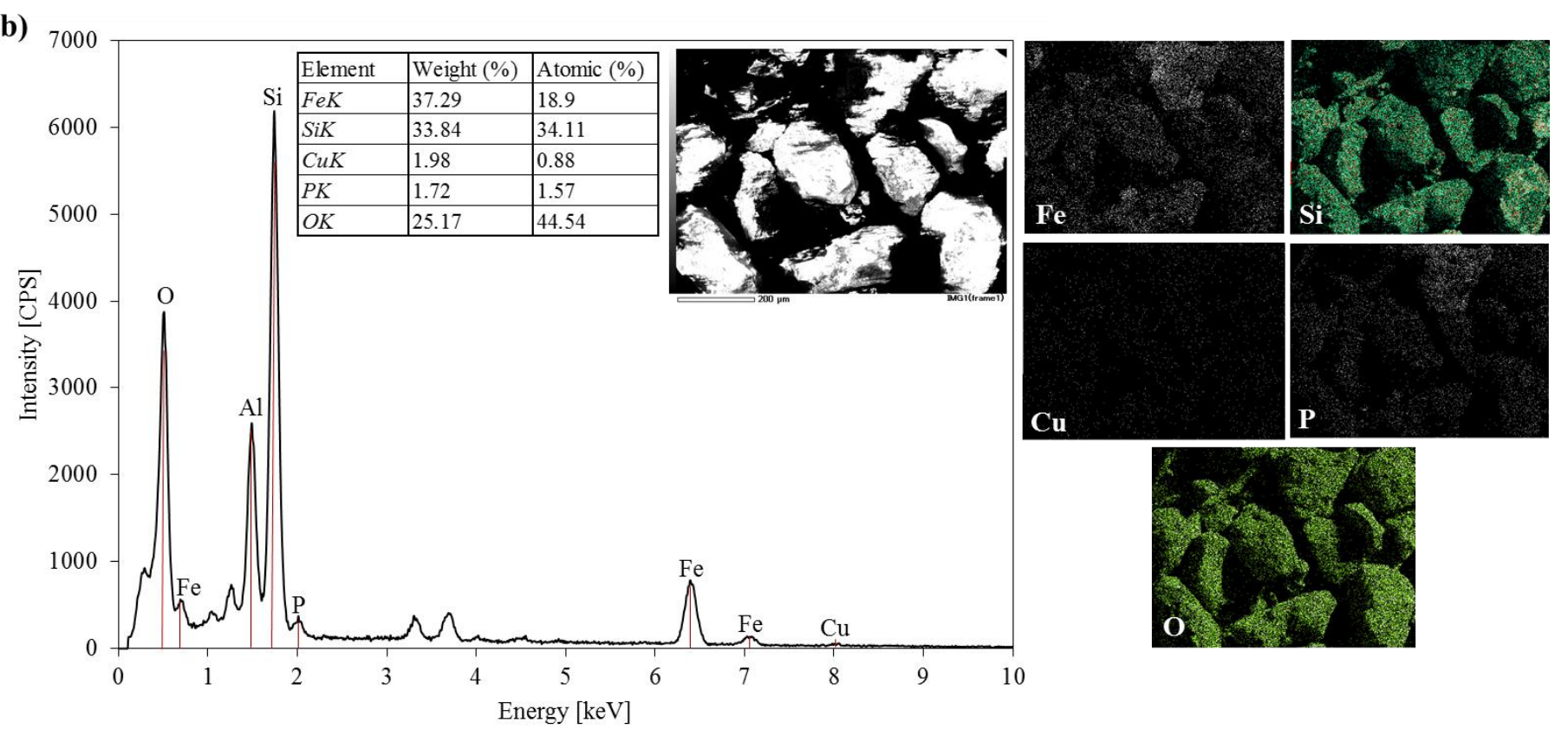

Fig. 5 SEM and EDX spectra of: (a) NZVI-sand (spent), and (b) NZVI/Cu-sand (spent)

\subsection{Column experiments}

In order to investigate the effect of different column configurations and operating conditions on the permeable reactive barriers design in terms of phosphorus removal efficiency was assessed by establishing different column configurations and operating was determined by laboratory microcosms (C1-C12). The removal performance of phosphorus was assessed through several comparisons in terms of the investigated factors. 
Phosphorus adsorption capacity and the removal efficiency were determined for comparing experiments performance. Phosphorus adsorption capacity $\left(q_{t}\right)$ was calculated following this formula:

$$
q_{t}=\frac{V\left(C_{o}-C_{t}\right)}{m}
$$

Where $\mathrm{C}_{\mathrm{o}}$ and $\mathrm{C}_{\mathrm{t}}(\mathrm{mg} / \mathrm{L})$ are initial and effluent phosphorus concentration, $\mathrm{m}(\mathrm{g})$ is reactive material dosage, and $\mathrm{V}(\mathrm{L})$ is accumulated inflow volume. While removal efficiency (R) was calculated based on (Eq. 4):

$$
R(\%)=\frac{C_{o}-C_{t}}{C_{o}} * 100 \%
$$

Moreover, the control column (C1) was considered in all comparisons as the reference in terms of performance for all column configurations.

\subsubsection{NZVI modification (NZVI vs. NZVI/Cu)}

Phosphorus adsorption capacity of NZVI and NZVI/Cu was investigated in experiment of 14-day duration in one-layer $20 \mathrm{~cm}$ in depth contains $20 \mathrm{~g}$ of NZVI mixed with river sand (C2), $20 \mathrm{~cm}$ in depth contains $10 \mathrm{~g}$ of $\mathrm{NZVI} / \mathrm{Cu}$ mixed with river sand (C4) and double-layer $10 \mathrm{~cm}$ in depth for each contains $10 \mathrm{~g}$ of NZVI mixed with river sand which are separated by $10 \mathrm{~cm}$ sand river layer (C3), $10 \mathrm{~cm}$ in depth for each layer contains 5 $\mathrm{g}$ of NZVI/Cu mixed with river sand which are separated by $10 \mathrm{~cm}$ sand river layer (C5) as shown in Fig. 6a and $6 \mathrm{~b}$ respectively. Results indicated that both NZVI and NZVI/Cu were effective in phosphorus removal from aqueous solution in porous media. The plotted data depicted that the four former columns containing reactive mixtures showed significantly higher phosphorus removal capacity over the whole experiment time compared to the control column $(\mathrm{C} 1)(\mathrm{P}<0.0001$ for $\mathrm{C} 2, \mathrm{C} 3, \mathrm{C} 4 \mathrm{vs} . \mathrm{C} 1)$ which reached saturation by the $10^{\text {th }}$ day. Meanwhile, the bimetallic nano-iron particles had a vital effect on phosphorus removal in comparison with NZVI ( $\mathrm{P}<0.0001$ for $\mathrm{C} 2$ vs. $\mathrm{C} 4$ and $\mathrm{C} 3$ vs. $\mathrm{C} 5)$. For the $\mathrm{NZVI/Cu}$ columns, maximum phosphorus adsorption capacity reached about 380 and $345\left(\mathrm{mg}-\mathrm{P} / \mathrm{g}-\mathrm{Fe}^{0}\right)$ in $\mathrm{C} 4$ and $\mathrm{C} 5$, while the values were lower than that in the NZVI columns (C2 and C3) with 173 and $223 \mathrm{mg}-\mathrm{P} / \mathrm{g}-\mathrm{Fe}^{0}$ respectively. Generally, the results confirmed that the addition of copper to NZVI resulted in doubling the phosphorus removal performance. The general trend in regards all columns (C1-C5) was an increase in the $\mathrm{pH}$ value (Fig. S2a, b). Concurrently, $\mathrm{pH}$ values in NZVI columns $(\mathrm{C} 2, \mathrm{C} 3)$ were slightly higher than that in control column $(\mathrm{C} 1)$ ranged between 8-8.5. Whereas, NZVI/Cu columns $(\mathrm{C} 4, \mathrm{C} 5)$ had lower values comparing with $\mathrm{C} 1$. The comparative improvement in phosphorus adsorption capacity and the reduction in $\mathrm{pH}$ values in $\mathrm{NZVI/Cu}$ columns could be interpreted by the reduction of the added copper ions $\left(\mathrm{Cu}^{2+}\right)$ to copper (Eq. 6), following by oxidation and precipitation reactions $($ Eq. 7,8$)$ which had a notable effect on reducing solution $\mathrm{pH}$ value due to the released $\mathrm{H}^{+}$protons (Khalil et al. 2016, Zeng et al. 2017, Eaton et al. 2005, Bard et al. 1980).

$$
\begin{aligned}
& \mathrm{Cu}^{2+}+2 \mathrm{e}^{-} \rightarrow \mathrm{Cu} \\
& 2 \mathrm{Cu}+\mathrm{H}_{2} \mathrm{O} \rightarrow \mathrm{Cu}_{2} \mathrm{O}+2 \mathrm{H}^{+} \\
& \mathrm{Cu}_{2} \mathrm{O}+\mathrm{H}_{2} \mathrm{O} \rightarrow 2 \mathrm{CuO}+2 \mathrm{H}^{+}
\end{aligned}
$$

The variation of effluent oxidation reduction potential (ORP) and dissolved oxygen (DO) values are exhibited in Fig. S3 and Fig. S4 respectively. The results show that the effluent ORP values in NZVI/Cu columns (either one or double-layer design) were higher than that of NZVI control columns (C1). In terms of the DO values, there were no significant $(\mathrm{P}=0.1931$ for $\mathrm{C} 2$ vs. $\mathrm{C} 4$ ) difference between the NZVI and NZVI/Cu columns 
except for the continuous fluctuation along the experiment time. However, comparing to the control column (C1), the presence of either NZVI or NZVI/Cu particles inside the other columns (C2-C5) had the main contribution in reducing the DO values due to the rapid aqueous corrosion and the formation of iron oxides $\left(\mathrm{Fe}^{2+} / \mathrm{Fe}^{3+}\right)$ according to (Eq. 9, 10).

$2 \mathrm{Fe}^{0}+4 \mathrm{H}^{+}+\mathrm{O}_{2} \rightarrow 2 \mathrm{Fe}^{2+}+2 \mathrm{H}_{2} \mathrm{O}$

$2 \mathrm{Fe}^{2+}+2 \mathrm{H}_{2} \mathrm{O} \rightarrow 2 \mathrm{Fe}^{3+}+2 \mathrm{H}_{2}+2 \mathrm{OH}^{-}$

Phosphorus concentration profiles along the columns after 14 days (see Fig. S5a, b in Supplementary Materials) confirmed the positive effect of using the bimetallic NZVI on phosphorus removal the C4 and C5 treatments comparing to the NZVI columns $(\mathrm{C} 2, \mathrm{C} 3)$ and the control column $(\mathrm{C} 1)$.
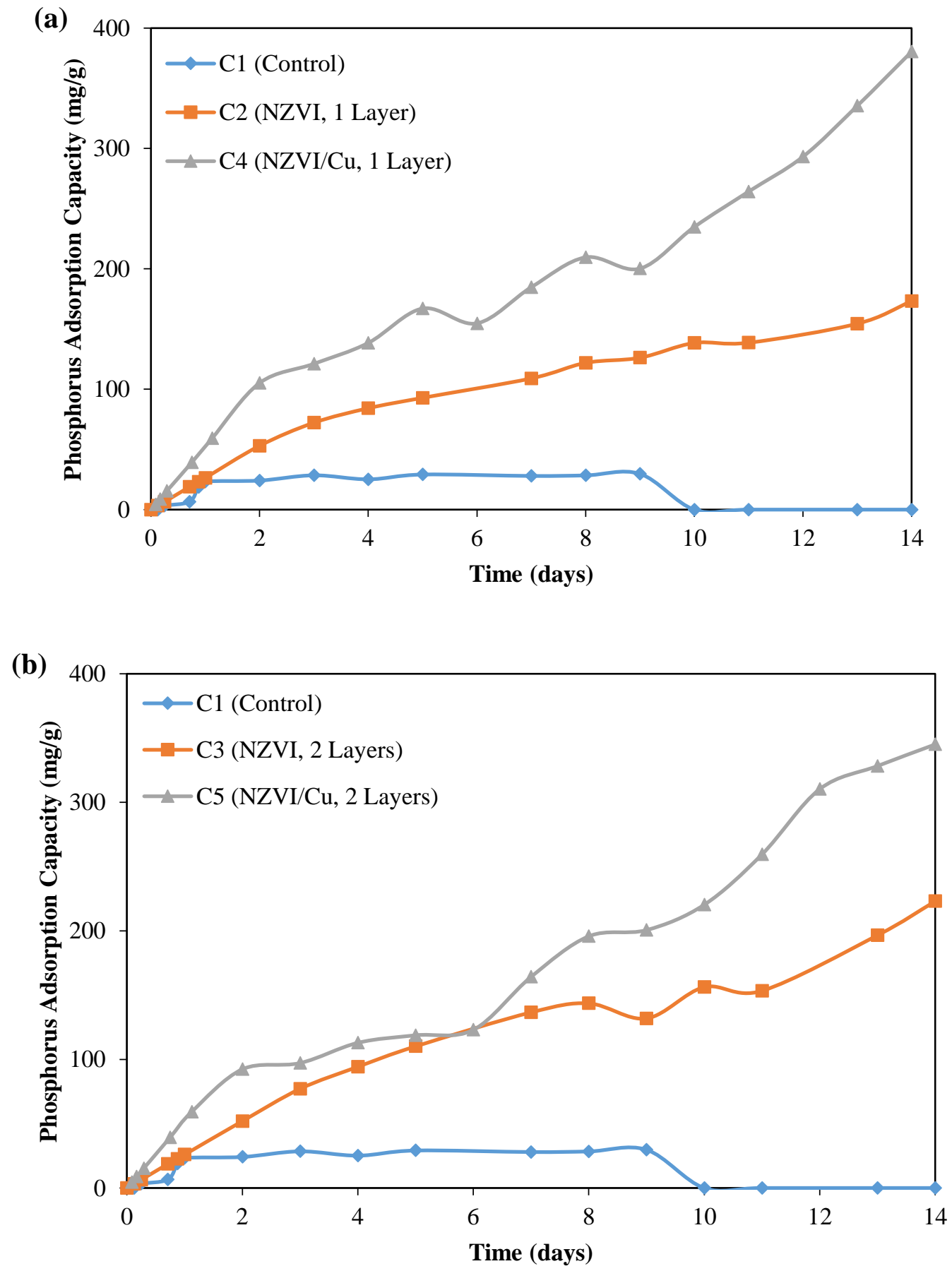
Fig. 6 Effect of modifying reactive material on phosphorus adsorption in: (a) one-layer, and (b) double-layer columns.

\subsubsection{Column configuration (one-layer vs. multi-layer)}

In order to investigate the effect of one/multi-layer configuration of PRB on phosphorus removal, adsorption capacity results for set no. 2 of experiments was considered. Plotted data in Fig. 7a and Fig. $7 \mathrm{~b}$ compares the phosphorus adsorption capacity between the NZVI and NZVI/Cu respectively, either one or double-layer column designs. For $\mathrm{C} 2$ and $\mathrm{C} 3(\mathrm{P}=0.2314$ for $\mathrm{C} 2$ vs. $\mathrm{C} 3)$, using NZVI as the reactive material in the mixture inside the two columns had no detectable difference with the first three days of the experiments. Afterward, the double-layer column design (C3) showed a slightly better performance than (C2) with one-layer design till the end of the experiments. In case of $\mathrm{NZVI} / \mathrm{Cu}$ columns, there was an unexpected increase in phosphorus adsorption capacity of one-layer column (C4) comparing with the double-layer column (C5) within the first 9 days of the experiments. Later, the difference fluctuation for the two curves was insignificant for the rest of the experiments $(\mathrm{P}=0.8021$ for $\mathrm{C} 4$ vs. $\mathrm{C} 5)$. The slight improvement in phosphorus removal which accompanied the double-layer design could be attributed to several possible explanations. Firstly, the presence of the separating sand layer between the two reactive layers enhanced phosphorus co-precipitation with the released iron oxides $\left(\mathrm{Fe}^{2+} / \mathrm{Fe}^{3+}\right)$ from the first reactive layer (Maamoun et al. 2018). Moreover, the clogging effect due to the occupation of the surface with the adsorbed compounds as well as the precipitates was decreased through sand layer and the contact time of phosphorus and reactive iron particles increased as a consequence. Generally, the influence of multi-layer design of PRB was not greatly observed on phosphorus removal performance.

Fig. S6a displays $\mathrm{pH}$ effluent results with respect to time for the two NZVI columns. As shown in the Figure, the $\mathrm{pH}$ values for the two columns ( $\mathrm{C} 2$ and $\mathrm{C} 3$ ) fluctuated too much to detect a trend in terms of design to the configuration. In contrast, $\mathrm{pH}$ values of $\mathrm{C} 4$ increased over the first three days compared with the two-layer column (C5) as shown in Fig. S6b. The $\mathrm{pH}$ values tended to decrease in NZVI/Cu columns comparing to NZVI columns for the same reasons explained in the previous section.

ORP and DO values of column effluent samples are displayed in Fig. S7 and Fig. S8 respectively. The results suggest that there were no detectable effect of the reactive layer design on either ORP or DO values except for the previously mentioned material effect. Column profiles of phosphorus concentration are presented in Fig. S9a, b (see the Supplementary Materials). 

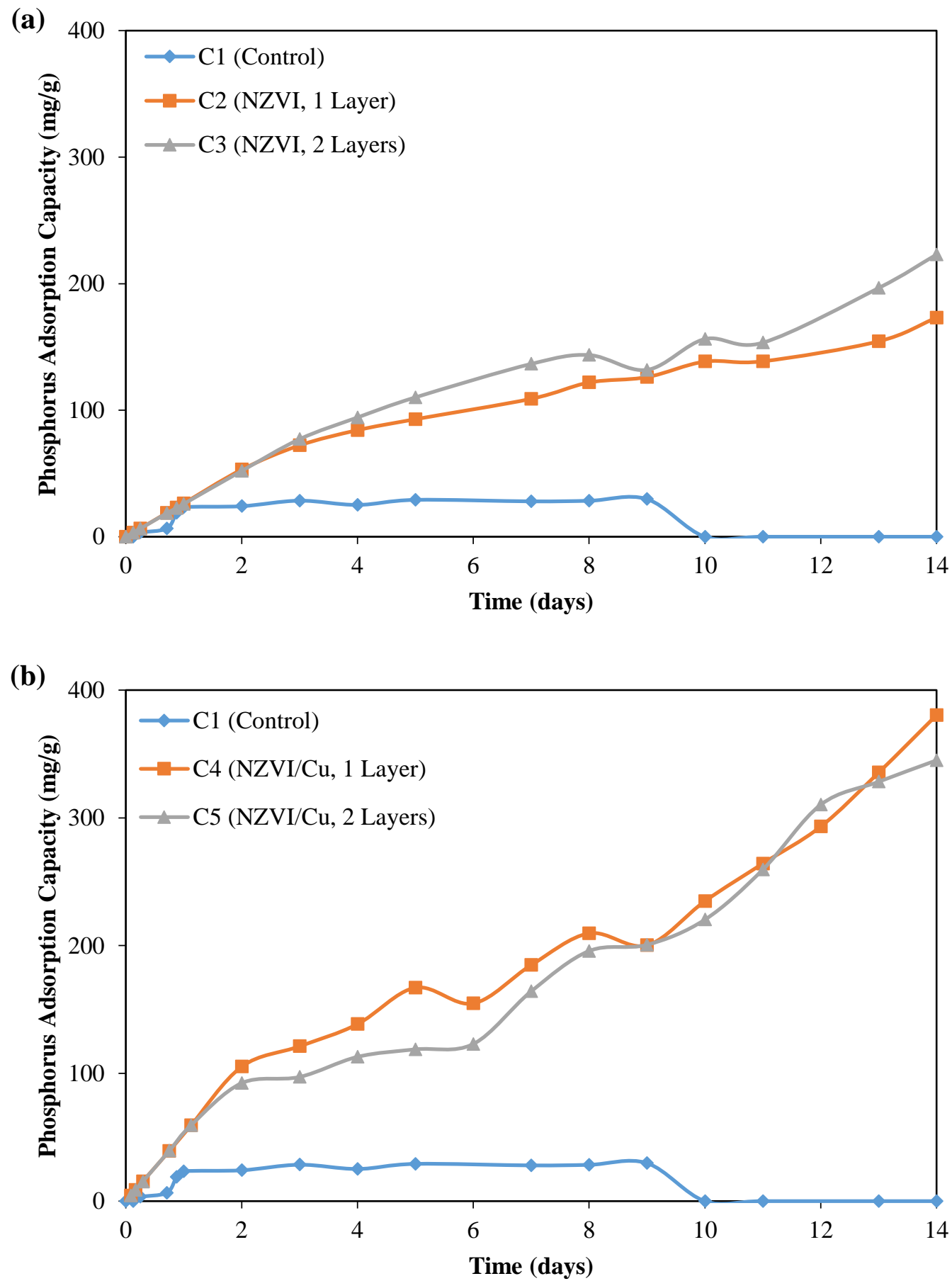

Fig. 7 Multi-layer effect on phosphorus adsorption in: (a) NZVI, and (b) NZVI/Cu columns.

\subsubsection{Reactive material state (mixture vs. pure vs. injection)}

The reactive material state was investigated by the comparison between three column experiments; one-layer $20 \mathrm{~cm}$ in depth contained $20 \mathrm{~g}$ of NZVI mixed with river sand fixed between two layers of river sand (C2), one-layer of $2 \mathrm{~cm}$ in depth containing $10 \mathrm{~g}$ of pure NZVI confined between two layers of river sand (C6) and the direct injection of $10 \mathrm{~g}$ pure NZVI at the top of column with a daily dose $2 \mathrm{~g}$ /day (C7). The effect of the NZVI state in the porous columns on phosphorus adsorption capacity is shown in Fig. 8. Up to the second day of the experiment, C6 which contained one pure layer of NZVI which was slightly more effective in phosphorus removal. The direct injection of pure NZVI at the top of column (C7) revealed a higher adsorption capacity compared to the mixture column $\mathrm{C} 2(\mathrm{P}<0.0001$ for $\mathrm{C} 2$ vs. $\mathrm{C} 7)$ whilst the direct injection $(\mathrm{C} 7)$ demonstrated a slightly similar capacity to the pure state column C6 ( $\mathrm{P}=0.1088$ for C6 vs. C7). In general, 
the change in reactive material status had an influence on phosphorus removal performance compared to column with pure and injection columns. Meanwhile, there were no observable significant differences observed in the $\mathrm{pH}$ and ORP results presented in Fig. S10a, b except for C6 in which pure NZVI showed lower values of $\mathrm{pH}$ and ORP compared to the other columns. Furthermore, the variation of dissolved oxygen (DO) values followed the same pattern (Fig. S10c). In contrast, Fig. S11 suggest that phosphorus concentration along the injection column (C7) were lower than that inside the other columns, which could be attributed to the fresh state of the injected (as-synthesized) NZVI slurry in addition to the possible surface oxidation of the particles during the packing process in C2 and C6. Overall the three different states of NZVI were effective at removing phosphorus but the best performance is dictated by the specific condition of the site. Nevertheless, it is suggested that the reactive mixture (NZVI/sand) with supporting material would be preferable for the long-term applications in terms of the cost and the high porosity comparing to the pure NZVI and the injection.

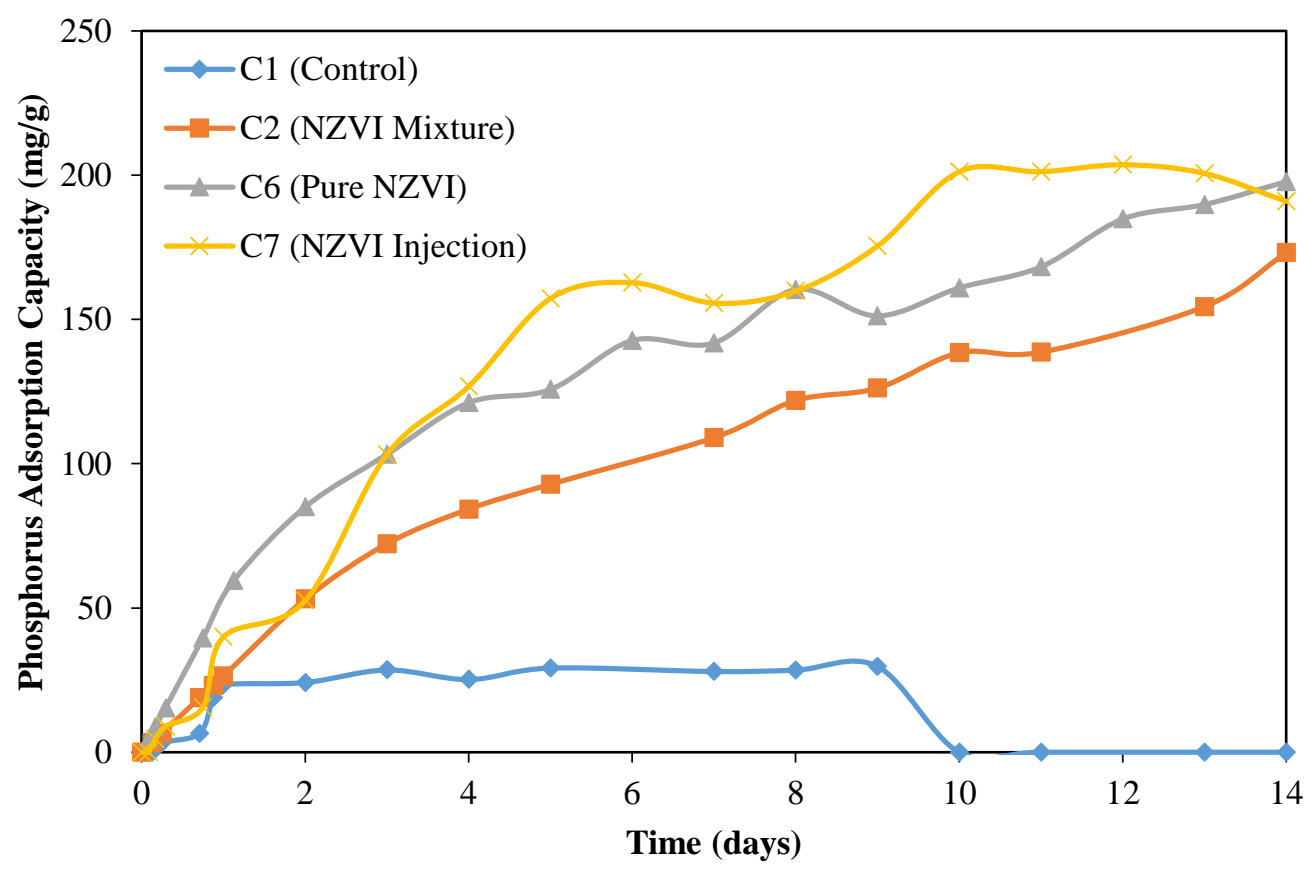

Fig. 8 Effect of reactive material state on phosphorus adsorption; mixture of NZVI/river sand layer (C2), pure NZVI layer (C6) and direct injection of pure NZVI (C7).

\subsubsection{Supporting material (river sand vs. standard sand)}

In addition, the potential bimetallic NZVI was investigated in supporting material (river sand/standard sand) in terms of its effectiveness in removal of phosphorus. Two Columns packed with reactive layer $20 \mathrm{~cm}$ in depth containing $10 \mathrm{~g}$ of NZVI/Cu was mixed with river sand (C4) or standard sand (C8). Fig. 9 shows phosphorus removal rate within the two columns (C4 and C8) in comparison with the control column $(\mathrm{C} 1)$. Results indicated that phosphorus removal efficiency was $98 \%$ in all columns for almost the first two days. Afterward, the removal rate declined in the river sand column (C4), whereas the breakthrough time in the column with standard sand (C8) as well as the control column (C1) was only 1 day. In subsequent days, the column (C4) filled with river sand showed better performance with final phosphorus removal rate of about $50 \%$, while it was around $14 \%$ in case of column (C8) filled with standard sand. This suggests that the river sand had nearly three-times the effectiveness in terms of phosphorus removal rate than standard sand over the 14 day study $(\mathrm{P}=0.1088$ for $\mathrm{C} 4$ vs. $\mathrm{C} 8)$.

The $\mathrm{pH}$ values revealed a steep increase at the beginning of the experiment reaching 8.6 in $(\mathrm{C} 8)$ with standard 
sand (Fig. S12a) and then stabilized to a neutral value. Whilst, the column with river sand (C4) showed lower $\mathrm{pH}$ values ranging between 5.6 to 7. It is worth mentioning that the control column (C1) had almost the same tendency of $\mathrm{C} 4$ except with a decrease in $\mathrm{pH}$ in the presence of $\mathrm{NZVI} / \mathrm{Cu}$. In the case of ORP results, standard sand showed a sharp decrease in ORP value in $\mathrm{C} 8$ to reach $-120 \mathrm{mV}$ within the first 12 hours, thereafter the value increased steeply fluctuating around $-40 \mathrm{mV}$ to end of the experiment (Fig. S12b). Whereas, the reduction rate of ORP values in $\mathrm{C} 1$ and $\mathrm{C} 4$ (containing river sand) was much lower than that of $\mathrm{C} 8$ (containing standard sand). Furthermore, dissolved oxygen (DO) results showed an expected decreasing in the two columns with NZVI/Cu (C4 and C8) compared to the control column (Fig. S12c). Additionally, the vertical phosphorus profiles confirmed that standard sand had a lower performance in terms of phosphorus decline than river sand with respect to phosphorus removal (Fig. S13). Overall it could be concluded that standard sand as a supporting material in the reactive mixture was less effective at phosphorus removal and this was attributed to the increase of $\mathrm{pH}$ values which affected removal efficiency. Moreover, the natural composition of the river sand which contained traces of aluminum ( $\mathrm{Al})$, sodium $(\mathrm{Na})$, and magnesium $(\mathrm{Mg})$, contributed acidic conditions which enhanced the phosphorus removal process. Overall, these results imply that supporting material in the reactive mixture is a crucial factor that is needed to be considered in the PRBs design.

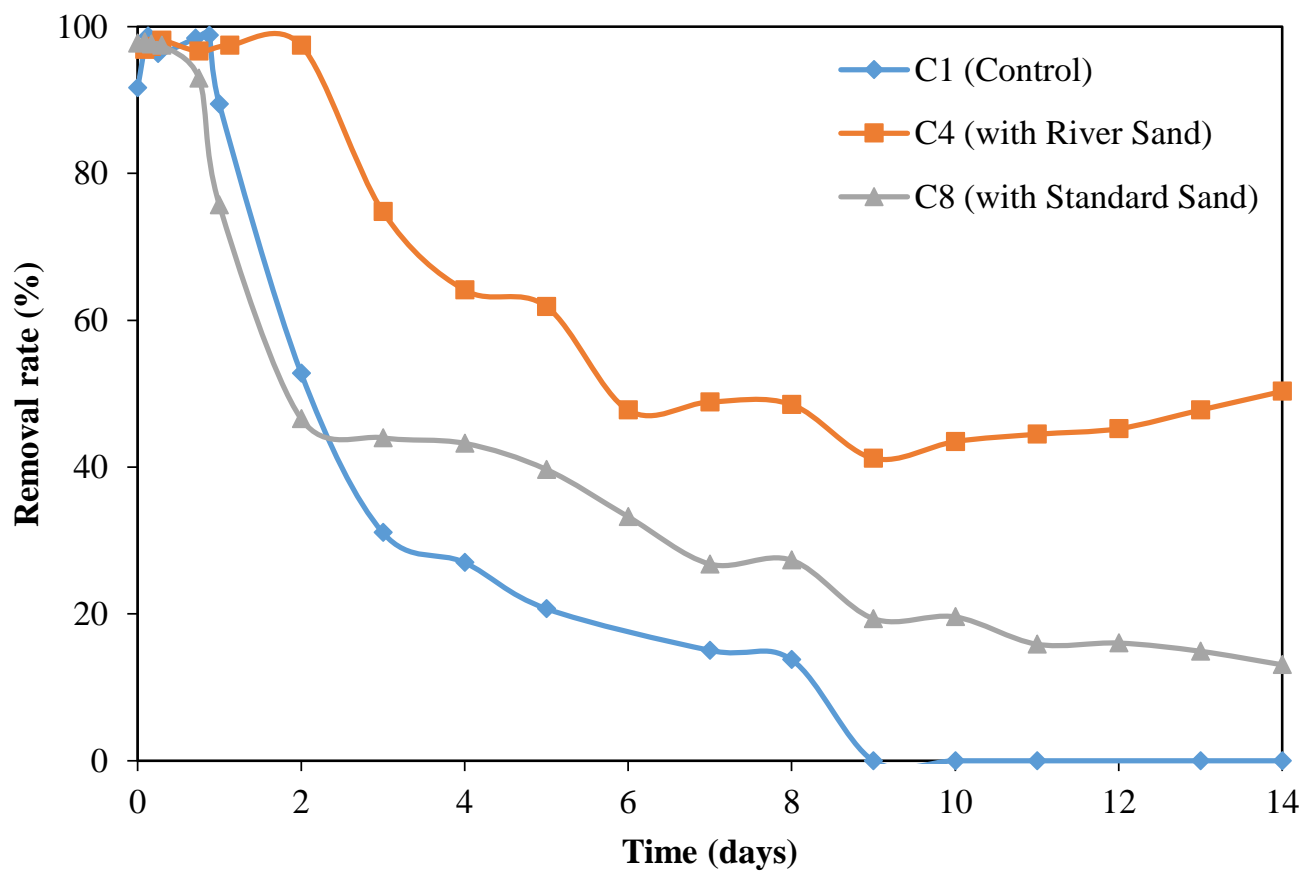

Fig. 9 Effect of supporting material on phosphorus removal rate.

\subsubsection{Flowrate (fixed vs. variable)}

Flowrate in the columns was investigated as it has a significant effect on the residence time of the reactive material inside the porous media. Fig. 10 shows phosphorus removal efficiency under constant and variable flowrates. The variation of the flowrate in C9 from 60 to $10 \mathrm{~mL} / \mathrm{min}$ over the experiment resulted in lower phosphorus removal rate compared to that of $\mathrm{C} 4$ with constant flowrate $(15 \mathrm{~mL} / \mathrm{min})(\mathrm{P}=0.0402$ for $\mathrm{C} 4 \mathrm{vs}$. C9). The removal rate was significantly low corresponding to the higher flowrate values in C9 within the first two days. Afterward, there was a dramatic enhancement in phosphorus removal after decreasing the flowrate to $10 \mathrm{~mL} / \mathrm{min}$. Over the second weeks of the experiment, there was a slight improvement in C9 performance in comparison with $\mathrm{C} 4$, indicating that the low flowrate inside the column had an obvious positive effect on 
phosphorus removal rate as a consequence of increased contact time between the reactive mixture and the phosphorus. Nevertheless, there was no significant influence of flowrate variation on the effluent $\mathrm{pH}, \mathrm{ORP}$, and DO values in Fig. S14a, b, and c respectively. Generally, the residence time of the reactive material inside the porous media seemed to be a critical factor in terms of the removal efficiency of phosphorus.

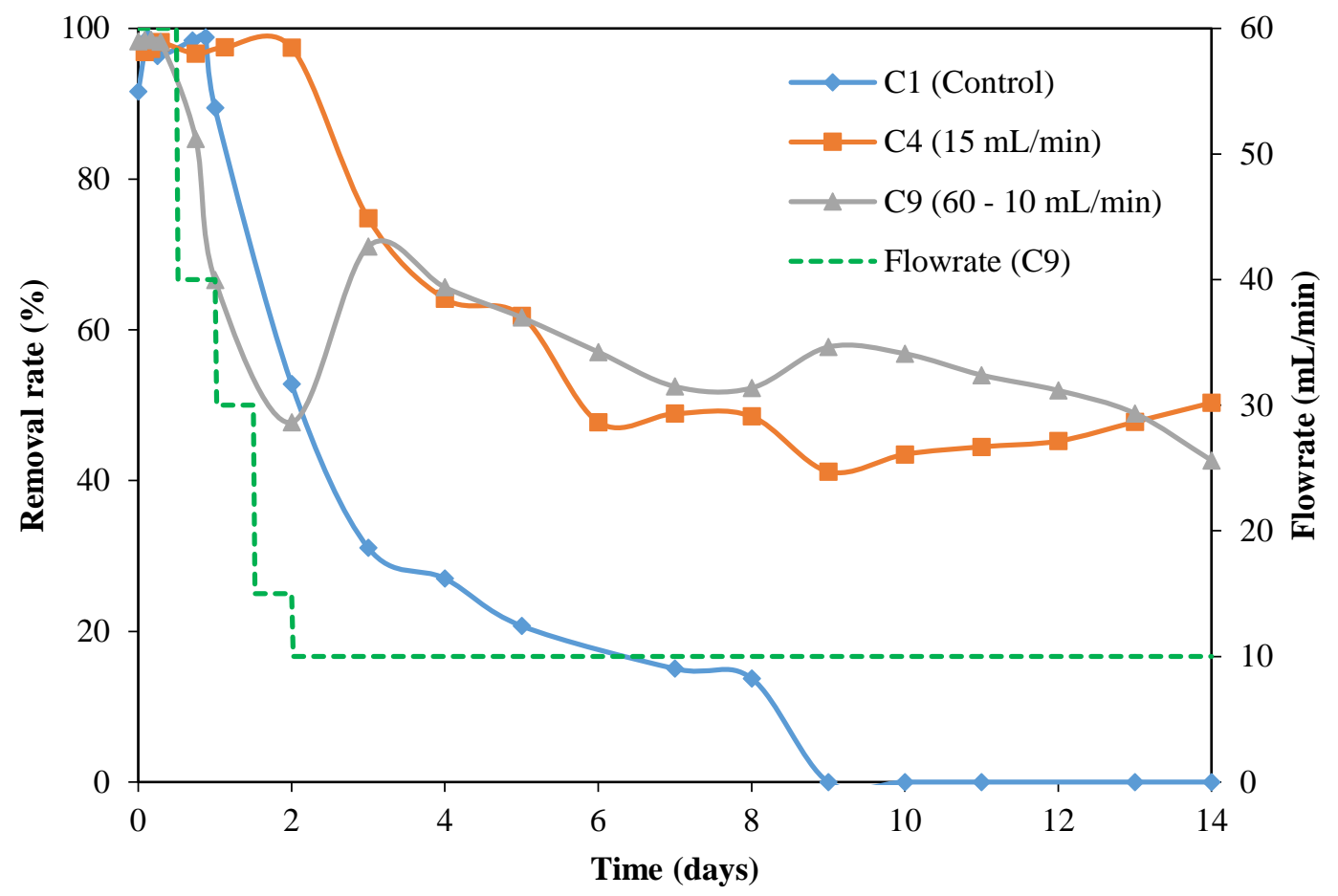

Fig. 10 Effect of flowrate variation inside the columns on phosphorus removal rate.

\subsubsection{Feeding solution (simulated $G W$ vs. P-solution)}

The sixth set of experiments was conducted in order to investigate the degree of interference of groundwater ions on phosphorus removal performance. The results of phosphorus adsorption capacity in Fig. 11 show that there was no detectable difference up to the first two days between $\mathrm{C} 4$ (with phosphorus solution influent) and $\mathrm{C} 10$ (with simulated groundwater influent) ( $\mathrm{P}=0.1051$ for $\mathrm{C} 4 \mathrm{vs} . \mathrm{C} 10)$. Afterward, the difference fluctuated to the end of the experiment whilst both showed a gradual increase. The interfering effect of groundwater ions was insignificant on phosphorus adsorption performance $( \pm 6 \%)$ which is correlated with other reported studies of unsupported NZVI (Almeelbi and Bezbaruah 2012). Effluent pH results showed a slightly higher values in C10 than that of C4 (Fig. S15a), whereas an inverse effect was observed for ORP values (Fig. S15b). This change may be attributed to the possible effect of groundwater ions in response to the high $\mathrm{pH}$ and low ORP conditions. In case of DO results, the reduction rate in the dissolved oxygen values with respect to the influent values in C4 and C10 were similar (Fig. S15c). Phosphorus concentration profiles of this experiment is provided in the supplementary materials (Fig. S16). 


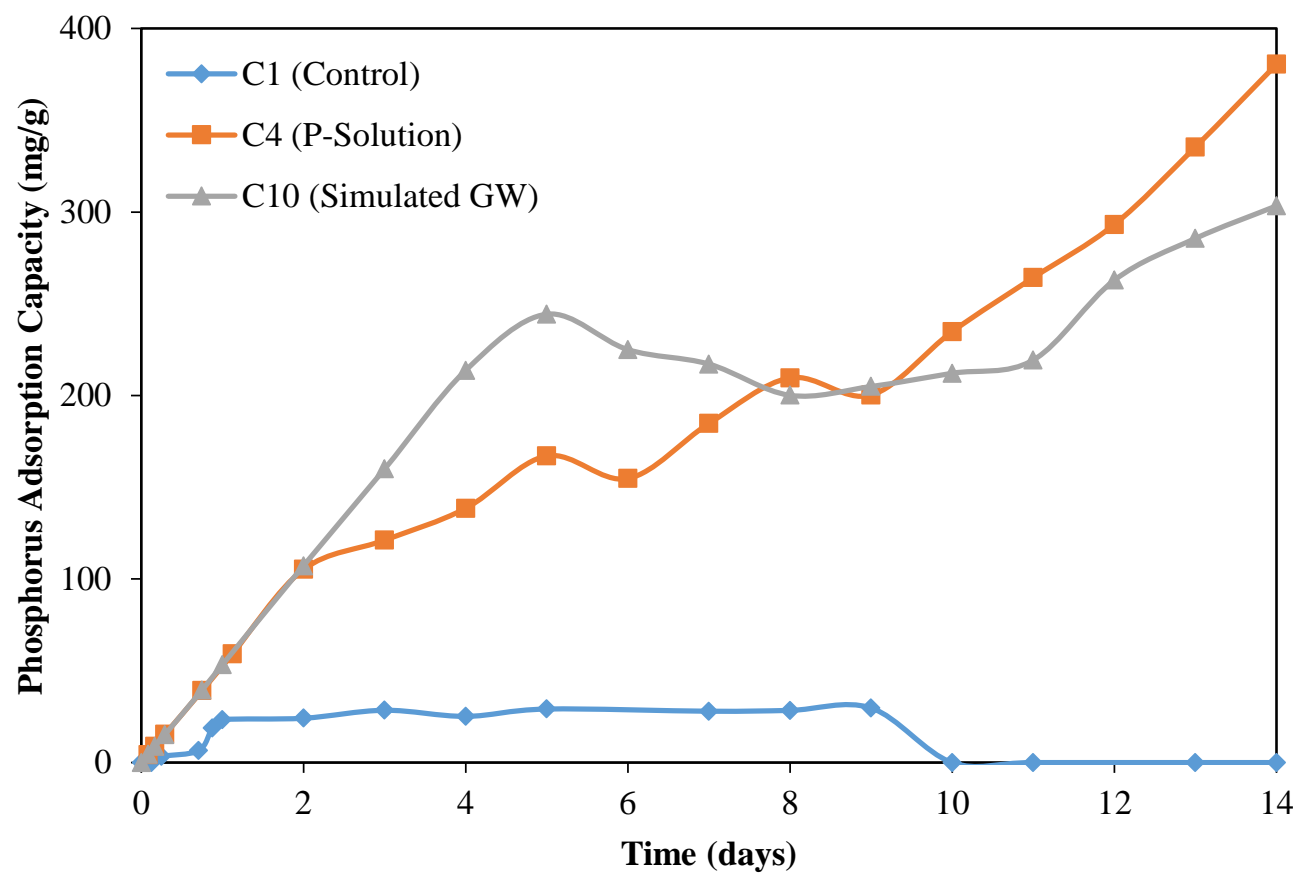

Fig. 11 Interference effect of groundwater ions on phosphorus adsorption.

\subsubsection{Long-term experiments (C11 vs. C12)}

The long-term phosphorus removal performance of the proposed reactive mixture (NZVI/sand and NZVI/Cusand) was investigated over 90 days' duration. The flowrate was adjusted to $5 \mathrm{~mL} / \mathrm{min}$ in order to increase the residence time of the reactive iron particles. Additionally, the double-layer design reactive layer was included since previous results suggested improvement in phosphorus removal when compared to the single-layer design. Results $\mathrm{s}$ in Fig. 12 indicate that there was no difference between the two columns in terms of phosphorus adsorption capacity within the first 15 days of the experiment. Over the following month, C11 with $\mathrm{NZVI} /$ sand reactive mixture demonstrated greater phosphate removal than $\mathrm{C} 12$ with the bimetallic reactive mixture reaching a maximum phosphorus adsorption capacity of $291 \mathrm{mg}-\mathrm{P} / \mathrm{g}-\mathrm{Fe}^{0}$. Nevertheless, adsorption capacity in $\mathrm{C} 11$ then dropped significantly during the last month and half while $\mathrm{C} 12$ showed a near stable removal performance. The reactive mixtures inside the two columns needed about 3 months to lose their phosphorus removal capacity suggesting the two columns were fully saturated once again with the initial phosphorus concentration after 90 days of the experiment. Generally, the long-term performance of both reactive mixtures were effective in phosphorus removal through porous media. The observed difference was not enough to determine a clear preference of one to another as they both showed a great potential on the longterm with an average phosphorus adsorption capacity over the 3 months of 143.34 and $128.76 \mathrm{mg}-\mathrm{P} / \mathrm{g}-\mathrm{Fe}^{0}$ for $\mathrm{C} 11$ and $\mathrm{C} 12$ respectively $(\mathrm{P}=0.0845$ for $\mathrm{C} 11$ vs. $\mathrm{C} 12)$. 


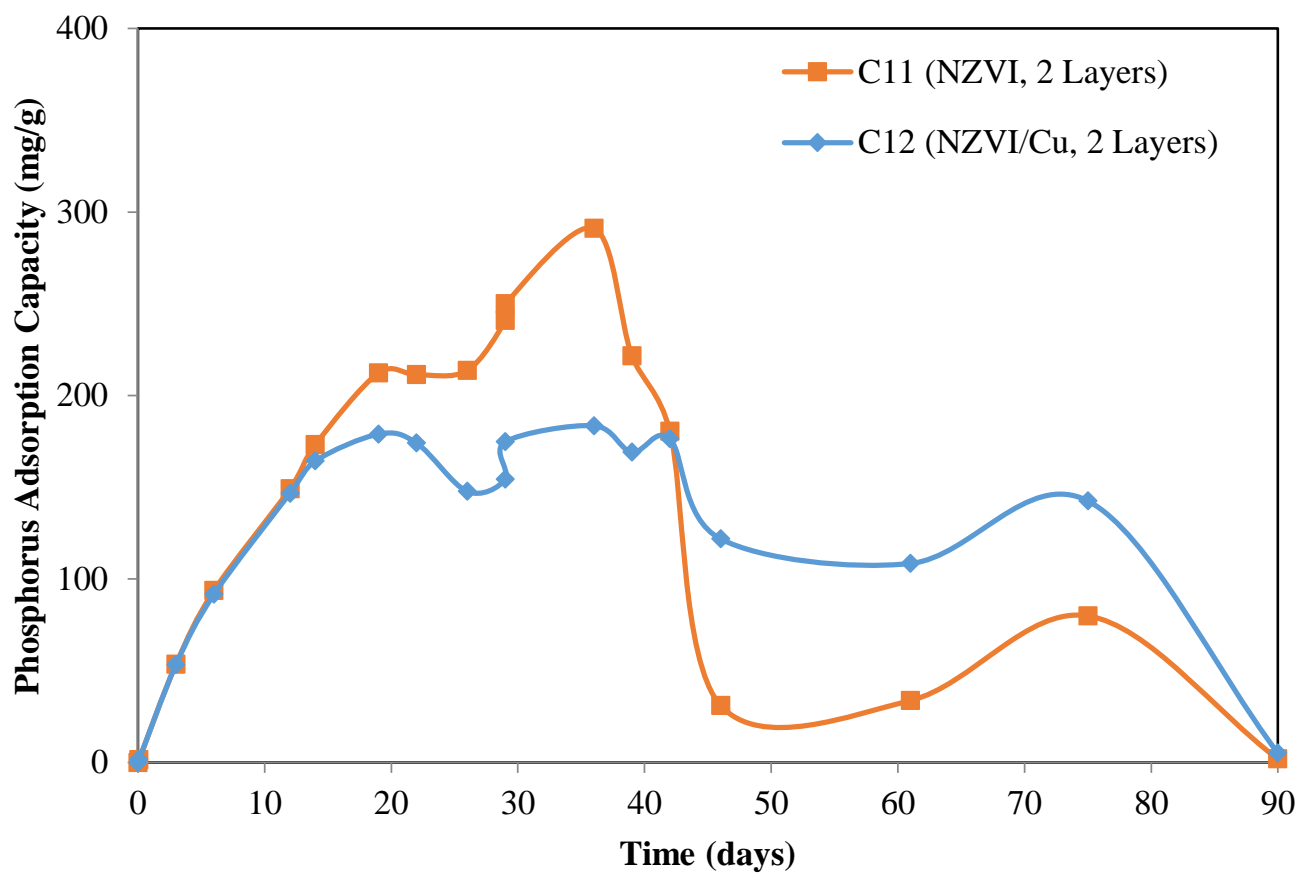

Fig. 12 Phosphorus adsorption capacities in long-term column experiments.

\section{Conclusions}

The main aim in this study was to propose a rational design of permeable reactive barrier (PRB) for phosphorus removal in porous media by NZVI through a bench-scale column experiment. Several design factors were investigated with respect to their influence on phosphorus removal. Employing either bare NZVI or the bimetallic one $(\mathrm{NZVI} / \mathrm{Cu})$ in the PRB's reactive mixtures resulted in a great enhancement in phosphorus removal comparing with the control column $(\mathrm{C} 1)$. Surface modification of NZVI particles with copper resulted in a smaller average size of the bimetallic particles $(24 \mathrm{~nm})$ comparing with bare NZVI (44 nm). Additionally, TEM morphology investigation confirmed the anti-aggregation effect in $\mathrm{NZVI/Cu}$ by an obvious discrete spherical particles comparing with the agglomerated clusters of bare NZVI. Results showed that maximum phosphorus adsorption capacity (mg-P/g-Fe ${ }^{0}$ increased by $54.47 \%$ and $35.36 \%$ in NZVI/Cu columns (C4 and C5) respectively, comparing with bare NZVI columns (C2 and C3). A slight enhancement in phosphorus removal was observed in the double-layered PRBs comparing with the one-layer design which could be attributed to the effect of separating sand layer between the two reactive layers on either the co-precipitation removal mechanism or the clogging phenomena. Moreover, The comparison between different delivery methods of NZVI into PRBs demonstrated that injecting reactive material into porous media could be the most effective technique corresponding to the highest overall phosphorus adsorption. However in terms of cost and high porosity effect, sand supported NZVI mixture might be preferable for long-term applications. Moreover, results suggested that river sand as a supporting material for NZVI in (C4) had a triple phosphorus removal rate over the 14 days experiment to that of standard sand in (C8), confirming the preferable effect of using river sand in NZVI reactive mixture. Retention time investigation indicated that low constant flowrate inside the column resulted in more contact time between the reactive mixture and the solute phosphorus which had a clear positive effect on phosphorus removal rate comparing with high or varied flowrates. The interfering effect of groundwater ions was barely observed on phosphorus adsorption performance $( \pm 6 \%)$ corresponding to the synthesized phosphorus solution. Furthermore, $\mathrm{pH}$ conditions proved to be a key factor during phosphorus removal processes in the presence of either NZVI or the bimetallic iron particles where acidic 
conditions were favorable for better phosphorus adsorption. Over a 90 days experiment, the observed difference between NZVI and NZVI/Cu was not enough to determine a clear preference of one to another as they both showed a great potential on the long-term with an average phosphorus adsorption capacity of 143.34 and $128.76 \mathrm{mg}-\mathrm{P} / \mathrm{g}-\mathrm{Fe}^{0}$ for $\mathrm{C} 11$ (with NZVI) and $\mathrm{C} 12$ (with NZVI/Cu) respectively. Generally, further studies should be performed based on an optimization model in order to integrate such presented results in the determination of the optimum design and conditions of PRBs towards better performance in the real in-situ remediation applications.

\section{References}

Eljamal, O., Okawauchi, J., Hiramatsu, K. and Harada, M. (2013) Phosphorus sorption from aqueous solution using natural materials. Environmental Earth Sciences 68(3), 859-863.

Cordell, D., Drangert, J.-O. and White, S. (2009) The story of phosphorus: global food security and food for thought. Global environmental change 19(2), 292-305.

Liu, H., Chen, T., Zou, X., Xie, Q., Qing, C., Chen, D. and Frost, R.L. (2013) Removal of phosphorus using NZVI derived from reducing natural goethite. Chemical Engineering Journal 234, 80-87.

Wen, Z., Zhang, Y. and Dai, C. (2014) Removal of phosphate from aqueous solution using nanoscale zerovalent iron (nZVI). Colloids and Surfaces A: Physicochemical and Engineering Aspects 457, 433-440.

Penn, C.J. and Warren, J.G. (2009) Investigating phosphorus sorption onto kaolinite using isothermal titration calorimetry. Soil Science Society of America Journal 73(2), 560-568.

Hauduc, H., Takács, I., Smith, S., Szabo, A., Murthy, S., Daigger, G. and Spérandio, M. (2015) A dynamic physicochemical model for chemical phosphorus removal. Water research 73, 157-170.

Eljamal, O., Okawauchi, J. and Hiramatsu, K. (2014) Product rich in phosphorus produced from phosphoruscontaminated water, pp. 261-265, Trans Tech Publ.

Mezenner, N.Y. and Bensmaili, A. (2009) Kinetics and thermodynamic study of phosphate adsorption on iron hydroxide-eggshell waste. Chemical Engineering Journal 147(2-3), 87-96.

Almeelbi, T. and Bezbaruah, A. (2012) Nanotechnology for Sustainable Development, pp. 197-210, Springer.

Eljamal, O., Okawauchi, J. and Hiramatsu, K. (2012) Removal of phosphorus from water using marble dust as sorbent material. Journal of Environmental Protection 3(8), 709.

Khalil, A.M., Eljamal, O., Amen, T.W., Sugihara, Y. and Matsunaga, N. (2017) Optimized nano-scale zero-valent iron supported on treated activated carbon for enhanced nitrate and phosphate removal from water. Chemical Engineering Journal 309, 349-365.

Khalil, A.M., Eljamal, O., Saha, B.B. and Matsunaga, N. (2018) Performance of nanoscale zero-valent iron in nitrate reduction from water using a laboratory-scale continuous-flow system. Chemosphere.

Tosco, T., Papini, M.P., Viggi, C.C. and Sethi, R. (2014) Nanoscale zerovalent iron particles for groundwater remediation: a review. Journal of Cleaner Production 77, 10-21.

Chitrakar, R., Tezuka, S., Sonoda, A., Sakane, K., Ooi, K. and Hirotsu, T. (2006) Phosphate adsorption on synthetic goethite and akaganeite. Journal of colloid and interface science 298(2), 602-608.

Hussain, S., Aziz, H.A., Isa, M.H., Ahmad, A., Van Leeuwen, J., Zou, L., Beecham, S. and Umar, M. (2011) Orthophosphate removal from domestic wastewater using limestone and granular activated carbon. Desalination 271(1-3), 265-272.

Eljamal, O., Khalil, A.M., Sugihara, Y. and Matsunaga, N. (2016) Phosphorus removal from aqueous solution by nanoscale zero valent iron in the presence of copper chloride. Chemical Engineering Journal 293, 225-231. 
Tu, Y.-J. and You, C.-F. (2014) Phosphorus adsorption onto green synthesized nano-bimetal ferrites: equilibrium, kinetic and thermodynamic investigation. Chemical Engineering Journal 251, 285-292.

Sleiman, N., Deluchat, V., Wazne, M., Mallet, M., Courtin-Nomade, A., Kazpard, V. and Baudu, M. (2016) Phosphate removal from aqueous solution using ZVI/sand bed reactor: Behavior and mechanism. Water research 99, 56-65.

Guan, X., Sun, Y., Qin, H., Li, J., Lo, I.M., He, D. and Dong, H. (2015) The limitations of applying zero-valent iron technology in contaminants sequestration and the corresponding countermeasures: the development in zerovalent iron technology in the last two decades (1994-2014). Water research 75, 224-248.

Lien, H.-L. and Zhang, W.-x. (2005) Hydrodechlorination of chlorinated ethanes by nanoscale Pd/Fe bimetallic particles. Journal of Environmental Engineering 131(1), 4-10.

Lien, H.-L. and Zhang, W.-X. (2007) Nanoscale Pd/Fe bimetallic particles: catalytic effects of palladium on hydrodechlorination. Applied Catalysis B: Environmental 77(1-2), 110-116.

Wang, X., Chen, C., Liu, H. and Ma, J. (2008) Preparation and characterization of PAA/PVDF membraneimmobilized $\mathrm{Pd} / \mathrm{Fe}$ nanoparticles for dechlorination of trichloroacetic acid. Water research 42(18), 4656-4664.

Schrick, B., Blough, J.L., Jones, A.D. and Mallouk, T.E. (2002) Hydrodechlorination of trichloroethylene to hydrocarbons using bimetallic nickel- iron nanoparticles. Chemistry of Materials 14(12), 5140-5147.

Xu, Y. and Zhang, W.-x. (2000) Subcolloidal Fe/Ag particles for reductive dehalogenation of chlorinated benzenes. Industrial \& engineering chemistry research 39(7), 2238-2244.

Khalil, A.M., Eljamal, O., Jribi, S. and Matsunaga, N. (2016) Promoting nitrate reduction kinetics by nanoscale zero valent iron in water via copper salt addition. Chemical Engineering Journal 287, 367-380.

Shubair, T., Eljamal, O., AhmedKhalil, M., Tahara, A. and Matsunaga, N. (2018a) Novel application of nanoscale zero valent iron and bimetallic nano-Fe/Cu particles for the treatment of cesium contaminated water. Journal of Environmental Chemical Engineering.

Shubair, T., Eljamal, O., Khalil, A.M. and Matsunaga, N. (2018b) Multilayer system of nanoscale zero valent iron and $\mathrm{Nano}-\mathrm{Fe} / \mathrm{Cu}$ particles for nitrate removal in porous media. Separation and Purification Technology 193, $242-254$.

Mak, M.S., Rao, P. and Lo, I.M. (2011) Zero-valent iron and iron oxide-coated sand as a combination for removal of co-present chromate and arsenate from groundwater with humic acid. Environmental pollution 159(2), 377382.

Ponder, S.M., Darab, J.G. and Mallouk, T.E. (2000) Remediation of Cr (VI) and Pb (II) aqueous solutions using supported, nanoscale zero-valent iron. Environmental science \& technology 34(12), 2564-2569.

Hwang, Y.-H., Kim, D.-G. and Shin, H.-S. (2011) Effects of synthesis conditions on the characteristics and reactivity of nano scale zero valent iron. Applied Catalysis B: Environmental 105(1-2), 144-150.

Zeng, Y., Walker, H. and Zhu, Q. (2017) Reduction of nitrate by $\mathrm{NaY}$ zeolite supported $\mathrm{Fe}, \mathrm{Cu} / \mathrm{Fe}$ and $\mathrm{Mn} / \mathrm{Fe}$ nanoparticles. Journal of hazardous materials 324, 605-616.

Eaton, A.D., Clesceri, L.S., Greenberg, A.E. and Franson, M.A.H. (2005) Standard methods for the examination of water and wastewater. American public health association 21, 1600.

Bard, A.J., Faulkner, L.R., Leddy, J. and Zoski, C.G. (1980) Electrochemical methods: fundamentals and applications, wiley New York.

Zhang, Y., Li, Y., Li, J., Hu, L. and Zheng, X. (2011) Enhanced removal of nitrate by a novel composite: nanoscale zero valent iron supported on pillared clay. Chemical Engineering Journal 171(2), 526-531.

Liu, Y., Majetich, S.A., Tilton, R.D., Sholl, D.S. and Lowry, G.V. (2005) TCE dechlorination rates, pathways, and 
efficiency of nanoscale iron particles with different properties. Environmental science \& technology 39(5), 1338-1345.

Yuvakkumar, R., Elango, V., Rajendran, V. and Kannan, N. (2011) Preparation and characterization of zero valent iron nanoparticles. Dig. J. Nanomater. Biostruct 6(4), 1771-1776.

Maamoun, I., Eljamal, O., Khalil, A.M.E., Sugihara, Y. and Matsunaga, N. (2018) Phosphate Removal Through Nano-Zero-Valent Iron Permeable Reactive Barrier; Column Experiment and Reactive Solute Transport Modeling. Transport in Porous Media 125(2), 395-412. 